\title{
Supporting awareness in communities of learning design practice
}

\author{
Konstantinos Michos ${ }^{1}$, Davinia Hernández-Leo \\ Department of Information and Communication Technologies, Universitat Pompeu Fabra, Roc \\ Boronat 138, 08018 Barcelona, Spain \\ \{kostas.michos, davinia.hernandez-leo\}@upf.edu
}

This is a pre-print of an accepted article submitted for consideration in Computers in Human Behavior.

Michos, K., Hernández-Leo, D. (in press). Supporting awareness in communities of learning design practice. Computers in Human Behavior. https://doi.org/10.1016/j.chb.2018.04.008

\footnotetext{
${ }^{1}$ Corresponding author. Email: kostas.michos@upf.edu
} 


\title{
Supporting awareness in communities of learning design practice
}

\begin{abstract}
The use of technology for the authoring of learning activities has been largely explored in the learning design field. However, the social dimension of the learning design process is still underexplored. In this paper, we investigate communities of teachers who used a social platform for learning design named ILDE. We seek to understand how community awareness facilitates teachers' learning design activity in different educational contexts. Following a design-based research methodology we developed the community awareness dashboard inILDE as a participation metaphor of the Cultural Historical Activity Theory (CHAT) framework. The dashboard displays behavioral interaction data of teachers with the platform regarding the objects-learning designs, the subjects-members and the mediating artifacts-tools. Evaluations were carried out in four different educational communities (two schools, master for pre-service teachers, MOOC for teachers). The community awareness dashboard was perceived useful to summarize the activity of the community, to identify content and members' roles. Dashboard use increased profile views in the environment and teachers showed willingness to build on others' contributions. Teachers' community reflection was present in school face-to-face discussions and tasks during the Massive Open Online Course. The lessons learnt lead to design principles for community awareness support based on the community context, practice-related insights, representations and visualization, tasks and community interests.
\end{abstract}

Keywords: Learning Design, awareness, activity theory, community of educators, community analytics, dashboards

\section{Introduction}

Learning Design (LD) or 'design for learning' is the field that studies how educators prepare and revise a set of learning activities towards more pedagogically informed decisions to achieve particular educational objectives (Mor, Craft, \& Hernández-Leo, 2013; Beetham \& Sharpe, 2013). LD research studies how technology tools support teachers' thinking for both the design and implementation of their learning activities (Bennett, Agostinho \& Lockyer, 2015; Hernandez-Leo et al., 2017; Celik \& Magoulas, 2016). The creation of explicit representations for the learning design process supported by different mediating artifacts such as patterns, models, case studies (Conole, 2008) aims to train the teachers/designers (Papanikolaou, Makri, \& Roussos, 2017) for the thorough thinking of the tasks carried out by them and the students during a learning session and the sharing of good practices within educational communities (Mor, Craft, Hernández-Leo, 2013). Although the design of learning units can be considered as an individual task of a teacher, the socio-cultural dimension of the learning design process, namely how teachers work and interact in small groups or larger educational communities to better inform their design tasks is still underexplored (Voogt et al., 2015; Bennett, Agostinho \& Lockyer, 2015; Asensio-Pérez et al., 2017; Michos \& Hernández-Leo, 2016). Different community environments enable teachers to design, share and re-use learning activities with learning design and authoring tools. LD community environments include the LAMS community (Dalziel, 2008), the Learning Designer (Laurillard et al., 2013), the LdShake (Hernández-Leo et al., 2014), the ILDE (Hernández-Leo et al., 2014), while related educational platforms integrate authoring tools for inquiry learning like WISE (Slotta \& Linn, 2009) and problem-based learning like the Instructional Architect (Recker, Yuan, \& Ye, 2014). Moreover, a collocated environment named EDS (Martinez-Maldonado et al., 2017) enables teachers to design in group learning scenarios with digital and non-digital devices. However, these environments lack the provision of mutual awareness to benefit from sharing among educators and community dynamics (Dalziel, 2013).

In this paper, we focus on the social perspective of learning design with the support of web-based platforms. The main addressed problem is to support awareness in distributed community environments 
for learning design by identifying appropriate analytical units. We carry out research in real-setting such as High and Vocational Schools and professional development programs (Master degree and Massive Open Online Course for teachers) to understand their application in different contexts. The different educational communities used an online community platform for learning design named Integrated Learning Design Environment (ILDE) (Hernández-Leo et al., 2014).

\subsection{Models and technology support in web-based educational communities}

Social environments are frequently used in educational settings for the management of educational resources and the creation of informal communities or networks of teachers. Two community models with application to teachers are the Communities of Practice (CoPs) (Wegner, 1998) and Professional Learning Communities (PLCs) (Vescio, Ross, \& Adams, 2008). CoPs are broadly defined as "groups of people who share an interest in a domain of human endeavour and engage in a process of collective learning that creates bonds between them" (Wegner, 1998, p.1), while PLCs aim to support educational practitioners' development by setting opportunities for the change of teachers' practices and as a result of their students' learning (Vescio, Ross, \& Adams, 2008). Technological support for web-based educational communities aims to respond to the individual and collective needs of teachers and help them to create learning processes in an atmosphere of openness (Lieberman \& Mace, 2010). Examples of such environments include wikis like EduOntoWiki, an environment for real-life narratives of educators build on ontologies (Petrucco, 2011), email groups like Mosaic Email Group; an online discussion group (Brown \& Munger, 2010), generic social networks like Twitter (Davis, 2015), webbased platforms like Cloudworks (Conole \& Culver, 2010) which enables the sharing of teaching ideas and teaching experiences, and learning management systems like Moodle (El-Hani \& Greca, 2013). Macià \& García (2016) summarize studies in networks of teachers and identify certain challenges both for the individuals and the whole community's performance. The barriers included peripheral participation, evolution of participation, the moderation of the community and professional development through the interaction between experienced users with newcomers. Moreover, teachers' time constraints and limited social support (Prenger, Poortman, \& Handelzalts, 2017) are factors which influence knowledge sharing and professional development in web-based teachers' communities. The above barriers are often discussed in the context of distributed environments as a problem of awareness and knowledge discovery (Soller, 2007) which is the focus of this paper.

\subsection{Linking frameworks of online (design) communities with learning design: the socio-cultural perspective}

Design communities include social structures that facilitate groups of people to share knowledge and resources for collaborative design (Fischer \& Ostwald, 2005). Usually interactions around boundary objects like design templates and reflective journals are used to trigger knowledge and communication within their members (Fischer \& Ostwald, 2005). In addition to CoPs and PLCs, Communities of Inquiry (Garrison \& Arbaugh, 2007) and Communities of Interest (CoIs) (Fischer, 2001) were applied to online design communities and communities of teachers. However, although all the above frameworks facilitate the understanding of the community as a whole and how members build common ground and their own identities, the identification of analytical units for connecting the individuals to the community activity system have been thoroughly addressed in models such as distributed cognition (Zhang \& Patel, 2006) and Cultural-Historical Activity Theory (CHAT) (Engeström, 2000). 
On the one hand, distributed cognition concerns with how cognitive activity is distributed across external cognitive artifacts, groups of people and how this happens across time and space (Belkadi et al., 2013). For instance, Carr, Johnson, \& Bush (2015) apply distributed cognition as a framework to understand the use of technological tools and their peers as extension of students' cognitive capacity. The framework helped to identify areas of improvement in learning outcomes and assessment of students. Distributed cognition and CHAT were both applied in social environments. However, some studies used the CHAT framework to describe the process of educators to design learning activities within a group or community. CHAT grounded on the Activity Theory is a sociocultural framework with increased attention in educational research and development (Gedera, \& Williams, 2015). Particularly, Conole (2008), Conole, McAndrew, \& Dimitriadis (2010) and Voogt et al. (2015) explain how CHAT is relevant in learning design and communities or groups of designers (see figure 1). The designer constitutes the subject who intends to create a learning activity or a learning design for a particular audience of students (individual level). For achieving this, the designer uses a range of mediating artefacts in different representations (case studies, patterns, models) which aim to capture pedagogical practice and can be specific learning design or authoring tools (technological level). The object to design a learning activity is the outcome of the learning design process and describes the overall intentions of the designer. Multiple subjects-designers with different motives may interact together with the mediating artifacts and the created learning scenarios within a community system like an educational institution or group of subject-specific teachers (community level). The interaction between the designers and the community is mediated by rules like the constraints of timetables in an educational institution or the norms and values of its members. Last, since the design of learning activities is a social process, the interaction between the community and the created learning designs is mediated by the specific roles of designers like head teachers and teachers or facilitators and members of professional development programs in a division of labour.

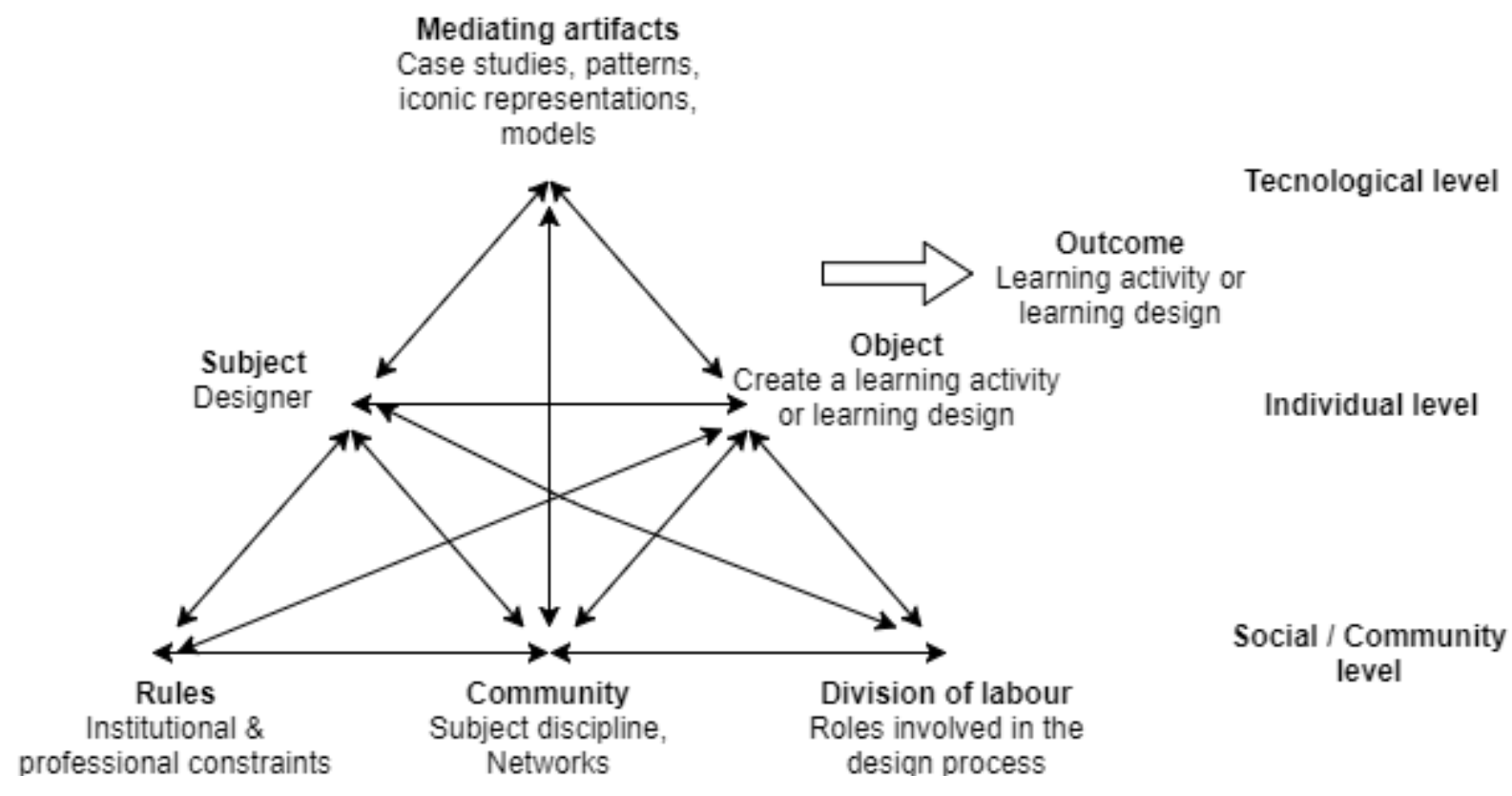

Figure 1. CHAT framework in communities of learning design (Conole, 2008, p. 198).

Although this framework provides a rich description on how groups of educators design learning activities by using various mediating artifacts or tools and how community members interact or repurpose the created learning activities of others, to our knowledge there is no specific study which applies this model to analyze and visualize the activity of social platforms for learning design. 


\subsection{Community awareness in learning design and authoring communities}

Design has been applied in multiple fields such as architecture and product design (MartinezMaldonado et al., 2017). Bearing in mind the social context of design in teacher practice, awareness plays an important role due to the design activities which are collaborative and multidisciplinary (Borges et al., 2005) and the need for shared knowledge between a group of people in the design of complex situations (Belkadi et al, 2005). Awareness has been broadly defined as "an understanding of the activities of others, which provides a context for your own activity" (Dourish \& Bellotti, 1992) or a "person's being or becoming aware of something" in a social context of interaction between individuals (Smidt, 2002). In groups of teachers, multidisciplinary teams may either include teachers, educational designers and researchers or different subject matter teachers who share a common interest and have different motives and preferences.

In addition to work teams, research on awareness has been conducted in larger communities (Koch, 2005; Saparova, Kibaru \& Bašić, 2013). For instance, in the educational context, Catteau et al. (2008) explain a system which provides awareness for a community of teachers and curriculum managers who use a learning object repository. They used two visualization techniques; 3D representations, tree map and a notification system to inform teachers how the learning objects evolve and becomes imported in a learning management system. Vassileva \& Sun (2007) developed community visualizations in the comtella system, an online community for sharing resources between university students, to stimulate their participation. They found that visual representations of members' contributions increased user participation. In workplace communities, interactive displays such as Community Mirrors shown in public spaces aim to show an aggregated and detailed view about the members of the community and their sharing resources (Koch, Ott, \& Richter, 2014).

Ruiz-Calleja et al. (2017) perform a literature review in Learning Analytics for workplace learning and identify publications with similar meaning like Community Analytics (Klamma, 2013) or Social Learning Analytics (Buckingham-Shum \& Ferguson, 2012) which were applied in different disciplines such as teacher learning. The papers were classified according to three learning metaphors: knowledge acquisition, participation and knowledge creation. Analytics for knowledge acquisition were providing feedback with visualizations relevant with the mismatch between workplace learning goals and progress. The participation metaphor was used to show awareness of a learning network or to provide information to community managers to increase participation. Lastly, the knowledge creation metaphor referred to analytics regarding the relationships between users, the artifacts and the actors.

\subsection{Research questions}

Although awareness tools and learning analytics were used to facilitate teaching and learning like supports for the collaborative learning of students (Janssen \& Bodemer, 2013) and teachers' orchestration (Martinez-Maldonado et al., 2012), little is known on how the presentation of community awareness data can facilitate groups of teachers in the design, sharing and re-use of learning activities within a social platform. This problem applies both to educational platforms that use specific learning design tools as well as to environments which use a variety of authoring tools. In both cases users can create, share and re-use the designed products within an individual and social space. In this paper, we seek to understand how the display of community awareness data can support teachers in their learning design process. Our research question and derived sub-research questions are:

RQ: How can community awareness data help teachers to support their learning design process?

RQ1: Which data and visualizations could be useful for teachers? 
RQ2: How can community awareness data be useful for the community and the individuals who are involved in learning design tasks?

Answering these research questions is articulated through interacting with users using a proposal of a community awareness dashboard to support understanding and awareness of a learning design community based on the CHAT framework. The ultimate goal is to support users (teachers, learning designers) to acquire aggregated and detailed information about the emerging activity of the actors (members), the created objects (learning designs) and the tools (various learning design, authoring tools, methodologies) within their web-based community.

\section{Methodology}

\subsection{Design based research}

Design-based research (DBR) provides flexibility and proposes analysis of requirements through the collaboration between educators and researchers in real-life settings to improve educational practices (Barab \& Squire, 2004; Wang, \& Hannafin, 2005; Anderson \& Shattuck, 2012). Our objective to develop community awareness support in the existing ILDE environment led us to follow this methodology (see Figure 2). Researchers in DBR methodology are involved in the everyday practice of the practitioners, rather than merely acting as observers and report results of their iterative cycles.

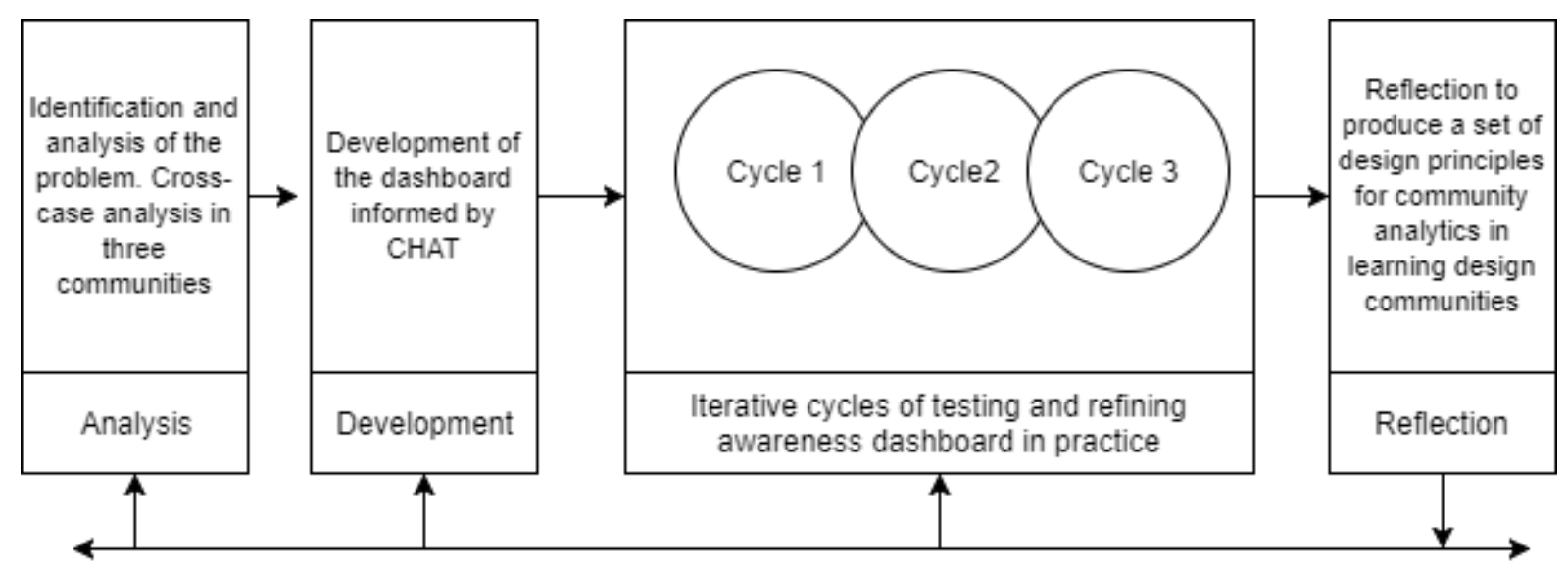

Figure 2. Overall design based research methodology to develop a community dashboard for web-based educational communities based on Barab \& Squire (2004).

In the first stage, we sought to elicit requirements for the development of community awareness support in an existing system. We carried out a cross-case analysis in three large groups of educators which used the ILDE (Michos \& Hernández-Leo, 2016). ILDE is a community environment for learning design, in which members can create, co-create and share designs spanning from the conceptualization of learning scenarios to their implementation (Hernández-Leo et al., 2014). The objective was to identify the engagement and interactivity levels of the members based on actor-artifact interactions (Reinhardt et al., 2009; Ludvigsen et al, 2015). Results of this study showed that the more divergent artifacts that the members of the community explore, the more they create artifacts (in this case learning designs with multiple tools). Moreover, social network analysis showed an influence of the users who create popular artifacts (many received views) in the overall community exploration of the content.

This initial analysis led us to explore further how awareness support in the different communities which use the ILDE facilitate members to identify dynamically content based on the emerging activity, to be aware of the main activity occurred within their community and how this supports their main tasks 
(exploration, creation, re-use, comments). We analyzed different frameworks which can explain the social dynamics in such design communities of teachers and collected initial feedback of users with respect to available or requested community awareness information in the existing environment. In the second stage, we proposed a community awareness dashboard with data visualizations based on CHAT. In the third stage, we performed 3 iterative cycles starting from the evaluation of prototypical data visualizations in Tableau with teachers until a pilot study with a functional dashboard integrated in the ILDE which shows real-time data visualizations in a community of teachers who participated in a Massive Open Online Course (MOOC) for learning design (See table 1 for the three iterative cycles and the context of teachers). We designed the community dashboard using the CHAT framework to articulate the representation of participation in learning design communities. In all the stages of the DBR methodology we documented the results to inform how a theoretical framework in learning design communities can be used to provide community awareness support in web-based communities of teachers.

Table 1. The three iterative cycles ("Development and iterative cycles" stages)

\begin{tabular}{llll}
\hline & Cycle 1 & Cycle 2 & Cycle 3 \\
\hline & $\begin{array}{l}\text { Initial prototypes in } \\
\text { Tableau }\end{array}$ & $\begin{array}{l}\text { Real-time visualizations in ILDE } \\
+ \text { prototypical visualizations about } \\
\text { tools }\end{array}$ & $\begin{array}{l}\text { Real time temporal } \\
\text { visualizations in ILDE / Pilot } \\
\text { study }\end{array}$ \\
Participants & 14 teachers & 9 teachers +22 pre-service teachers & $\begin{array}{l}209 \text { participants- } 49 \text { active } \\
\text { teachers/users }\end{array}$ \\
Community & School community & $\begin{array}{l}\text { School community + Pre-service } \\
\text { teacher community }\end{array}$ & MOOC community \\
\hline
\end{tabular}

\subsection{Participants in Cycle 1}

\section{School 1}

Teachers $(N=25)$ in Secondary and Vocational education schools were involved in a professional development program about learning design. The participants used the ILDE in a series of face-to-face workshops and online activities from November 2016 until June 2017. The facilitators of the program prepared 6 face-to-face 2-hour workshops with individual and group activities in the ILDE. The topics of the workshops were about collaborative learning, problem-based learning, teacher inquiry and learning analytics. Teachers were asked to complete the design of learning activities and implement them with their students, to document classroom activities and share material with their colleagues. Many teachers used authoring tools to design their learning activities in follow up participation without the instructions of the facilitators. In workshop 4, after 4 months of the program, participants were presented with a prototypical community dashboard which was showing data visualizations of their past activities in ILDE.

\subsection{Participants in Cycle 2}

\section{School 2 \& Master course for pre-service secondary teachers}

Teachers in School $2(N=9)$ and pre-service teachers $(N=27)$ participated in this cycle. School 2 participated in a professional development program, similar to the program followed by School 1, with a series of 4 face-to-face workshops and online activities with the support of ILDE. The topics of the workshops were the same than in School 1. Participants were presented in the third workshop with a community dashboard integrated in ILDE. Pre-service teachers were involved in a master course about 
Biology teaching in Secondary schools. They used the ILDE during the whole year to share material with their colleagues and the tutors and to prepare and document their classroom practice. In the final session, they were presented with the community dashboard integrated in ILDE.

\subsection{Participants in Cycle 3}

Teachers in a Massive Open Online Course (MOOC) for the design of collaborative learning with ICT

Teachers $(N=209)$ registered in the ILDE during a MOOC which lasted 6 weeks. The name of the MOOC was "Innovative collaborative learning with ICT"1 and aimed to train teachers in the design and implementation of collaborative learning scenarios with technology. Participants carried out their design activities in ILDE and used Canvas LMS as the main MOOC platform. In the second week of the MOOC participants were presented with the community dashboard with temporal analytics (filtered by dates) and were asked to carry out some tasks (e.g. commenting on others' resources and designs). In week 4 participants used different authoring tools to design their collaborative learning situations and were presented with a visualization about the use of tools by their MOOC community.

\subsection{Data collection instruments in the different stages of the DBR methodology}

We performed literature review in all the stages of the methodology and collected data from divergent sources following a mixed-method methodology (questionnaires, field notes, group discussion transcripts, log data from ILDE). Mixed-method enables joint analysis and triangulation of quantitative and qualitative data (Creswell \& Plano Clark, 2007). Quantitative analysis with descriptive and inferential statistics was conducted using IBM SPSS 22 while log file analysis was performed with Heidi SQL and Tableau software. Qualitative data analysis was used to deepen analysis in teachers' perception about community awareness information. Analysis was performed in the open responses of the questionnaires, group discussion transcripts and teachers' comments in the MOOC. Open coding was developed to identify the main topics of teachers' responses (Strauss \& Corbin, 1998). The research was carried out in collaboration with the ILDE users in the different educational communities (Table 2).

Table 2. Data collections methods, participants and purposes

\begin{tabular}{|c|c|c|c|}
\hline $\begin{array}{l}\text { DBR Stage } \\
\text { (see Figure 1) }\end{array}$ & Data collection methods & Participants & Purpose \\
\hline Analysis & $\begin{array}{l}\text { Literature review } \\
\text { Log file analysis } \\
\text { Questionnaire }\end{array}$ & $\begin{array}{l}2 \text { MOOC communities + } 1 \\
\text { open community (Michos \& } \\
\text { Hernández-Leo, 2016). } \\
\text { School } 1 \text { - School } 2\end{array}$ & $\begin{array}{l}\text { Identification and } \\
\text { analysis of the } \\
\text { problems in the use } \\
\text { of the community } \\
\text { environment }\end{array}$ \\
\hline Development & $\begin{array}{l}\text { Literature review } \\
\text { Questionnaire }\end{array}$ & School 1 - School 2 & $\begin{array}{l}\text { How to support } \\
\text { community } \\
\text { awareness based on } \\
\text { CHAT in alignment } \\
\text { with ILDE features } \\
\text { and collected data }\end{array}$ \\
\hline Iterative cycles & $\begin{array}{l}\text { Questionnaire, voice } \\
\text { discussion recordings, field } \\
\text { notes. } \\
\text { Log file analysis }\end{array}$ & $\begin{array}{l}\text { School 1- School } 2 \\
\text { Master Course } \\
\text { MOOC participants }\end{array}$ & $\begin{array}{l}\text { Perceived usefulness } \\
\text { and user experience } \\
\text { testing } \\
\text { Real-case scenario }\end{array}$ \\
\hline
\end{tabular}

\footnotetext{
${ }^{1}$ https://www.canvas.net/browse/valladolid-en/courses/innovative-collaborative-learning-en
} 
Task behavior

\begin{tabular}{llc}
\hline Design elements & $\begin{array}{l}\text { Reflection from iterative } \\
\text { cycles }\end{array}$ & Design principles \\
\hline
\end{tabular}

\section{Results}

This section reports first the results of the analysis stage (see table 2), then follows the development and iterative cycles stages in which the community awareness dashboard was evaluated in the different educational communities.

\section{1 "Analysis" stage}

Our initial analysis with data sets of different communities in ILDE (Michos \& Hernández-Leo, 2016) showed that the exploration of different artifacts, the popular content and users influenced re-use and creation of learning activities and designs. During this stage, we gathered initial feedback from school teachers in School 1 and School 2 to better understand to what extent ILDE facilitates awareness about the main activities carried out in the platform and which types of data are more interesting for the teachers involved in their community. The feedback was gathered with a post-questionnaire with closed and open questions in Workshop 3 in each School 1 and School 2. In this stage requirement analysis was conducted and elements of CHAT were examined in teachers' responses.

The main topics from the teachers' responses in the open questions were that, for those of them having sufficient time to use the environment, ILDE facilitated awareness of other members' activity because it supports the sharing, review of learning designs and browsing by educational topics. They also mentioned that ILDE helps them to access learning designs from the perspective of another teaching area and provides useful information when teachers are involved in joint work. One teacher pointed out that the environment helps to access learning activities designed by others which could be a starting point for his own created activities (see Table A1 in the Appendix).

"It helps because it is easy to explore and browse the designs of other members" [T1], "Yes, it helps to see the activities designed from the perspective of another area of education" [T8].

Last, teachers proposed additional data that could be associated to designs and would be interesting for their school community, like the impression of their students about their implemented designs, issues that worked well or not during their implementation, subject-specific designs by educational level and the most-used and most-visited designs (see Table A2).

"Yes. [I would like to know ...] What are the most used designs, whether it has worked or not ... to know the contents that worked better" [T18]. "Yes. [I would like to know ...] those that have been most interesting for the students" [T14].

The main reported problem from teachers was that time restrictions did not allow frequent exploration and sharing of designs. Their open responses showed some first elements of the CHAT framework. Sharing of teachers' artifacts was indicated valuable to understand how other teachers design their learning situations based on different methodologies and this shows interest for the social space of the environment. Teachers revealed that sharing helps to build on the designed learning activities of others. The ultimate target of their designs were their students as they specified that they want to know how 
students perceive the learning activities and what happens in the classroom implementation. Identifying popular content and learning designs relevant to their teaching subject was also a common response. As such, the initial motivations of the teachers referred to the sharing of learning designs, the students' impressions and the identification of relevant and popular topics as emerge from their community.

\section{2 "Development and iterative cycles" stages}

\subsubsection{InILDE: A community awareness dashboard for learning design communities based on CHAT}

Analysis of teachers' perception about awareness information in two schools suggested that the limited time, teacher motivation and preferences are critical aspects that affect the social perspective of the community. This analysis drove the development of a prototypical community awareness dashboard with real datasets of the School 1 and School 2. Our rationale was to first develop the community dashboard based on the CHAT units of analysis as relevant to understand participation and interactions in learning design communities and second to evaluate the feasibility of the approach with the collected data in ILDE (e.g. initial behavioral data). The process which we followed was to use data from the platform and classify them as activity indicators for the members, designs and tools.

For the metaphor of the name, we used the prefix in (inside the Integrated Learning Design Environment- inILDE) and as a motive to encourage users to investigate their community (see Figure 3 ). We designed three separated tabs regarding the objects-learning designs (designs tab), the subjectsmembers (members tab) and the mediating artifacts-tools (tools tab). A tab including both members and designs was used to display combined information. In each tab, we proposed aggregated activity awareness data about the designs, the members and the tools and detailed awareness data regarding common users' actions in the environment (e.g. create, explore, comment, re-use). The aim was to align the provided information with the performed actions by the users.

The designs tab included aggregated data about the different attributes of the created learning designs (original, re-used, public, explored from different members) aiming to support understanding on how designs were created or explored by others within the community. Detailed information included the 10 most viewed designs (requested from teachers) and the 10 most re-used designs with the titles and authors' name. This information intended to show how emerging exploration and re-use of designs indicated periodically the common interests of the community. Last, a radial tidy tree visualization showed connections between the original and the duplicated designs of all the community (see Figure 3). The aim was to visualize how teachers' build on each other contributions.

The members tab included aggregated data about the different members' characteristics (total registered members, contributors, commenters, publishers) to support understanding of the different actions performed by the community members. Detailed awareness information was provided about the 10 top contributors of the community by counting the amount of created learning designs and the 10 top commenters by counting the amount of comments aiming to identify periodically the key contributors and active participants in the community.

The tools tab included aggregated data about the amount of designs created by the different tools of ILDE in the last 10 days. The visualization showed dots with different colors which represented different tools in ILDE and different sizes which represented the amount of learning designs created by each tool. Figure 3 shows the dashboard in each of the 3 iterative cycles from initial prototypes to the integration in ILDE. 


\section{Cycle 1}

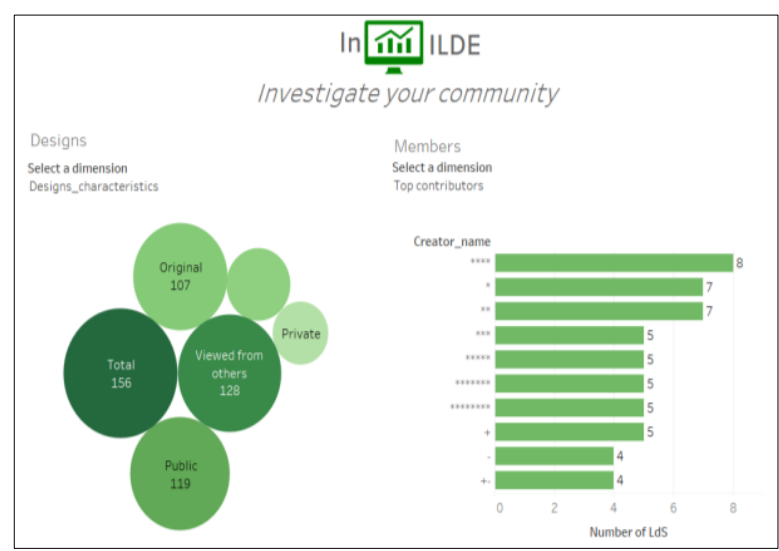

\section{Cycle 2}

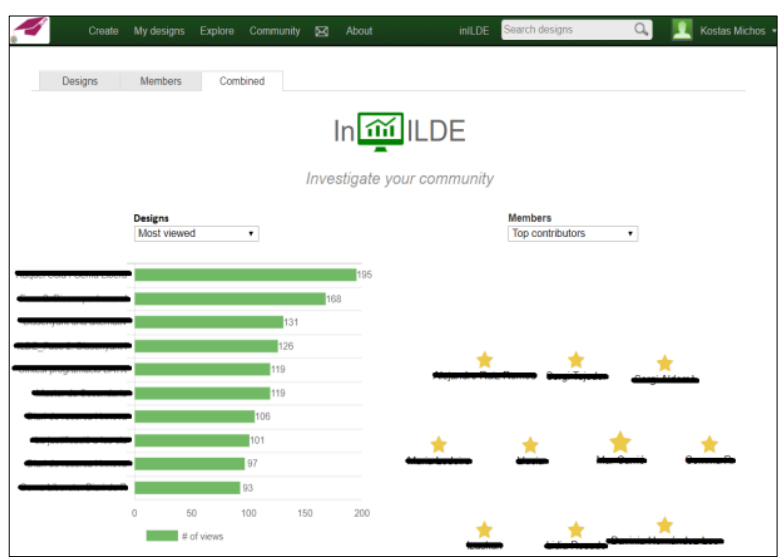

\section{Cycle 3}

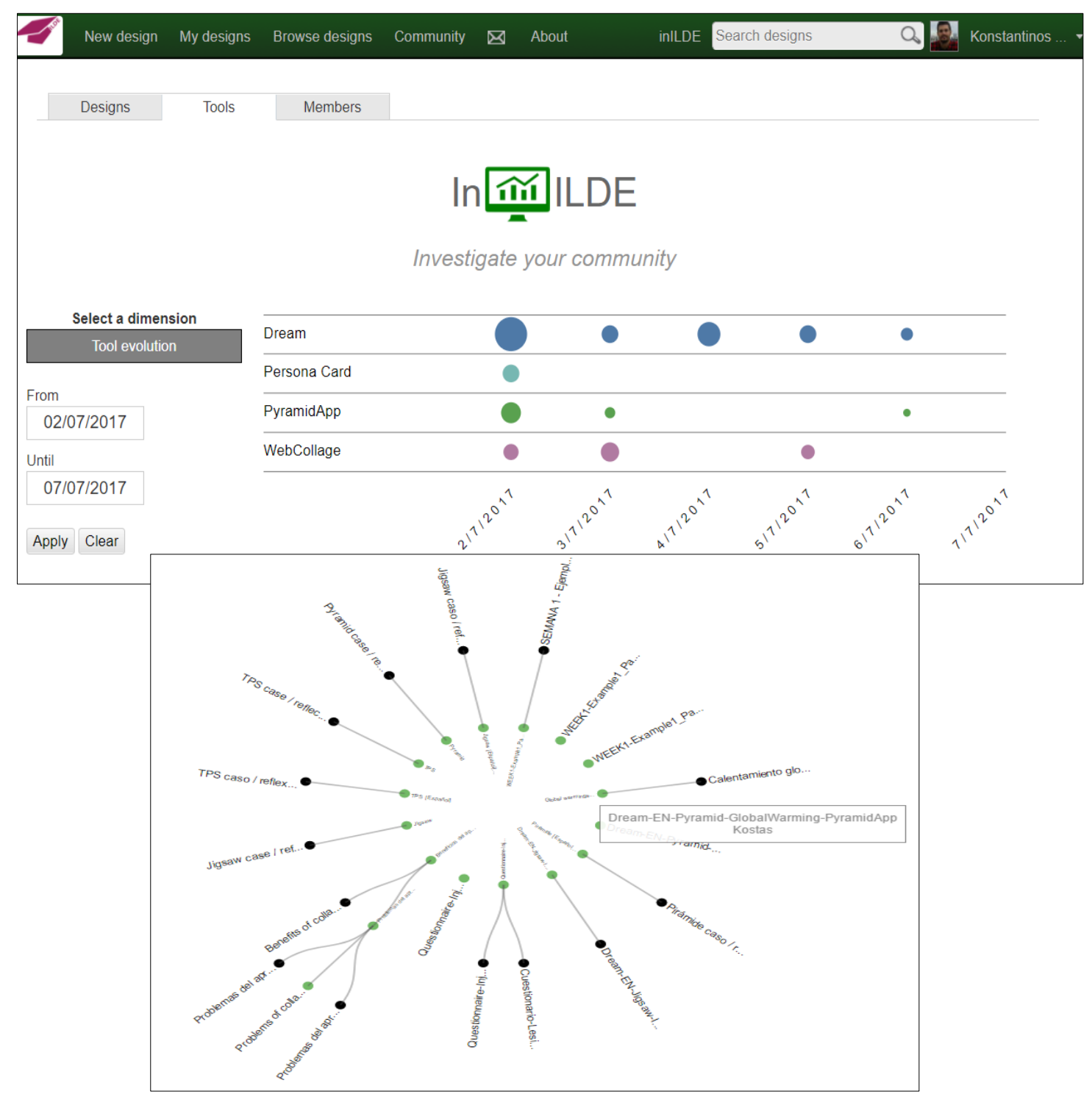

Figure 3. Screenshots of the community awareness dashboard in the three iterative cycles. Cycle 1: Prototypes in Tableau, Cycle 2: Implemented visualizations in the interface of ILDE, Cycle 3: Integrated temporal visualization in the interface of ILDE. 


\subsubsection{Cycle 1: First prototypical visualizations}

Teachers $(N=14)$ in School 1 evaluated the usefulness of this information for their educational community. During the 3rd workshop, we demonstrated and explained the community dashboard. Then users had time to explore and navigate through the prototypes. A post-questionnaire for evaluation was shown next to the prototypes. The questionnaire included closed and open-ended questions about the usefulness of the different proposed tabs and visualizations for specific use cases like the identification of active members in the community and the most interesting designs. Participants were also asked to explain negative, positive features and recommendations for improvement. Participants reactions were documented from one individual researcher.

Teachers rated all the visualizations with means ranging between 3.08-4.33 in a Likert scale 1-5 showing that they appreciated the majority of the presented information in the dashboard. The most highly rated was a barchart which showed the most viewed designs of the community $(M=4.33$, $S D=0.91)$ following by the most re-used designs $(M=4.25, S D=0.82)$. The fact that this graph showed more detailed information like the title and name of creator as opposed to the aggregated information which showed only numbers and the different categories may have influenced their opinion. However, the members tab in overall $(M=4, S D=0.61)$ was perceived more useful compared to the designs tab $(M=3.66, S D=0.94)$. This result suggests that teachers are especially interested to know the participation of the members in the community. The lowest rating was given to a radial tidy tree representation which showed the original and duplicated designs of the community. The fact that teachers were presented with synthetic data in this case may have influenced the understandability of this visualization. The open-ended responses yielded better insights for teachers' opinion.

Regarding the designs tab, teachers' main positive responses were that it helped them to have a quick summary on what is happening in their community and it saved their time to search designs in ILDE. They also pointed out that the most used and most viewed designs may help them to find interesting designs in the community. As negative aspects, one of the teachers explained that in a heterogeneous community in which teachers are experts in different subjects the most-used designs or the most-popular designs are not necessarily as valuable as those designs relevant to their specific subject area. The ILDE supports this type of exploration with the use of tags for semantic content but this information was not visualized in the dashboard. Barcharts as visualization for the main contributors was also mentioned as a negative aspect because it introduces a comparison between teachers which was stated as unnecessary. They also recommended that the graphs should be associated as links with the designs in ILDE and that they would find it even more useful if the community dashboard is used in larger communities which include different schools (see Table A3).

"The information to find the most used or duplicated designs is interesting, maybe it could directly appear the works or designs properly linking with them." [T32], "The positive aspect is that from this platform I can see the summary of my community in a dynamic and fast way, but as a negative point is that if my community is very heterogeneous in terms of the subjects which we represent, some tools are not useful for me." [T34]

Regarding the members tab teachers explained that it facilitated understanding of the overall members' participation and the finding of influential members who use specific learning designs tools. It also helped them to identify the roles of the different members within this community. Negative comments were about the inconsistency of active members and their subject expertise as some teachers wanted to find designs related to their subject. Other responses acknowledged that quantitative data sometimes are not useful and access to the specific comments or contributions would provide more interesting 
information. The teachers recommended that this tab can be used as social advice to follow active members of this community and facilitates interaction between active and inactive members (see Table $\mathrm{A} 3)$.

"Positive: it helps us see the degree of participation of the members of the community. Negative: From here we cannot (directly) access their contributions." [T55], "They are very visual and stand out the most active members and the ones who make the most out of it. It may be useful to identify users who do not benefit from the tool and check for possible improvements." [T50]

Regarding the visualizations we presented three prototypes of the dashboard with different graphical representations and colors. Teachers pointed out that they prefer the prototypes which showed different colors in the visualizations as it helps them to find quickly the information. Bubble charts were perceived more dynamic and with less space as opposed to tree maps.

During the demonstration of the dashboard, field notes of one individual researcher reveal that teachers showed enthusiasm when the community data were presented. One of the teachers commented: "I am not even in the list!", meaning that his name did not appear in the contributors' visualization. When teachers were presented with the visualization about the most active commenters, many teachers started to laugh and look at the person who appeared to have more comments. The above face-to-face reactions of the teachers show that the visualizations included information which were not obvious in the platform.

\subsubsection{Cycle 2: Visualizations integrated in ILDE}

In the second cycle, we implemented the dashboard in the interface of the social platform ILDE considering the feasibility of the approach (collected data in ILDE, estimation of new data to be collected, presentation of the data) (see Figure 3, Cycle 2). In this prototype, real-time visualizations about the members and designs were shown as a community dashboard in ILDE. The java script libraries $\mathrm{d} 3$.js and chart.js were used for the development while prototypical visualizations about the use of the tools were designed in Tableau. We considered all the initial feedback from School 1 and we re-designed our first prototypes. For instance, we redesigned members' contributions visualizations from bar charts to a visualization with growing stars as proposed by Vassileva \& Sun (2007) aiming to stimulate users' participation.

Teachers in School $2(N=9)$ and pre-service teachers in the master course $(N=27)$ evaluated the community dashboard inILDE in Cycle 2. In the school, teachers were presented with the dashboard after a series of 4 workshops while in the master degree in the final session of the course. In the school, after the demonstration of the dashboard, teachers were involved in a discussion about the use of the community awareness dashboard. One of the teachers explained that such awareness tools could be used to understand which colleagues work and design together during the year and which were the main topics and most useful tools. The teacher stated that this promotes community culture in their school (see Table A4).

Regarding the designs tab the teachers of the school community mentioned as positive aspects the overview of the activity in their community and as support for joint work within their school. The teachers claimed in this school that they prefer to access more qualitative information than statistics and would be interesting to know the level of elaboration of the different learning designs. The pre-service teachers appreciated that the dashboard depicts a general idea about the designs created during their master course (see Table A5). 
"It allows a joint vision." [T58], "It helps me to see the designs globally." [T80], "It's only a statistical tool, it does not allow access to the designs." [T58]

Regarding the members tab, teachers mentioned that it helps to identify productive members and potential experts in a tool but visualization which classify teachers in categories might create inappropriate identities. The pre-service teachers explained that they could identify the most influential members within their course community but they would also like to have access to learning designs with joint authorship and the comments of the members (see Table A5).

"A positive aspect would be that it allows identifying a colleague who is more expert in the use of a particular tool, to ask, consult or share methodologies, doubts, etc" [T73]. "You can see people who comment more on the designs" [PT95].

Last, regarding the tools tabs both pre-and in-service teachers mentioned that is interesting to know who used the different tools and it helped them to assess the different tools of the platform.

I think it would be important to identify who has created with the different tools, because in case I am interested in working in something similar, I will be able to identify the creator and if necessary contact him." [T100], "This tab is interesting to see the trend of what is being used in ILDE." [PT102].

3.2.4 Cycle 3: Pilot study in a Massive Open Online Course for teachers. Blending the community dashboard with learning design tasks

In the third cycle, we redesigned the inILDE community dashboard based on the feedback gathered in Cycle 1, 2. Changes were the links to the artifacts or members from the visualizations, the implementation of visualizations about the use of tools and filtering of the data by dates (see Figure 3, Cycle 3). The objective of this cycle was to test the community dashboard during a longer period and evaluate the effects in community members' behavior (exploration, creation, re-use, comments) and user experience. 209 participants registered in the ILDE during the Massive Open Online Course "Innovative collaborative learning with ICT" which lasted 6 weeks. Out of 209, 100 participants created at least one artifact in the environment.

In this cycle, we designed an experiment to evaluate the differences in individual and community behavior and user experience after using the dashboard. The objective was to understand how the community awareness dashboard facilitates members to: a) perform common actions in the environment (explore, re-use, create, comment designs) and b) perform the epistemic tasks proposed by the facilitators of the MOOC. For the evaluation, we used the logs of ILDE, comments of users during the tasks of the MOOC and a post-questionnaire with closed and open questions. Table 3 shows the different tasks during the MOOC and the weeks in which participants had access to the dashboard.

The design of the experiment was as follows:

a. 1 week use of ILDE without the inILDE community dashboard

b. 5 weeks use of ILDE with the dashboard

c. Task supported by the dashboard during the second week of the MOOC (comment learning designs with and without the use of the dashboard)

d. Subjective usability of the dashboard with the Usability Metric for User Experience (UMUX) (Finstad, 2010). It is a four item likert scale aimed to measure the three dimensions of usability: effectiveness, efficiency and satisfaction. Open-ended questions regarding the support for the users' tasks and the overall experience. 
Table 3. Main tasks in ILDE and access to the dashboard during the MOOC

\begin{tabular}{|c|c|c|c|c|c|c|}
\hline & $\begin{array}{l}\text { Week } 1 \\
\text { 12/06-19/06 }\end{array}$ & $\begin{array}{l}\text { Week } 2 \\
\text { 19/06-26/06 }\end{array}$ & $\begin{array}{l}\text { Week 3 } \\
\text { 26/06-03/07 }\end{array}$ & $\begin{array}{l}\text { Week } 4 \\
\text { 03/07-10/07 }\end{array}$ & $\begin{array}{l}\text { Week } 5 \\
\text { 10/07-17/07 }\end{array}$ & $\begin{array}{l}\text { Week } 6 \\
17 / 07-24 / 07\end{array}$ \\
\hline Tasks & $\begin{array}{l}\text { Explore and } \\
\text { comment } \\
\text { examples of } \\
\text { collaborative } \\
\text { learning. Re- } \\
\text { use a design } \\
\text { pattern for } \\
\text { collaborative } \\
\text { learning and } \\
\text { describe your } \\
\text { case. }\end{array}$ & $\begin{array}{l}\text { Explore the } \\
\text { social features } \\
\text { of ILDE. } \\
\text { Comment a } \\
\text { case of another } \\
\text { participant. } \\
\text { Comment a } \\
\text { case after using } \\
\text { the dashboard. }\end{array}$ & $\begin{array}{l}\text { Re-use and edit } \\
\text { your own } \\
\text { design for } \\
\text { collaborative } \\
\text { learning } \\
\text { (Pyramid } \\
\text { pattern). }\end{array}$ & $\begin{array}{l}\text { Re-use and edit } \\
\text { your own } \\
\text { design for } \\
\text { collaborative } \\
\text { learning } \\
\text { (Jigsaw } \\
\text { pattern). }\end{array}$ & $\begin{array}{l}\text { Create your } \\
\text { own complete } \\
\text { Learning } \\
\text { Design (LD) } \\
\text { project. }\end{array}$ & $\begin{array}{l}\text { Evaluate two } \\
\text { other LD } \\
\text { projects. }\end{array}$ \\
\hline $\begin{array}{l}\text { Awareness } \\
\text { dashboard }\end{array}$ & $\begin{array}{l}\text { No access to } \\
\text { the dashboard. }\end{array}$ & $\begin{array}{l}\text { Access to the } \\
\text { dashboard. } \\
\text { Instructors } \\
\text { triggered } \\
\text { dashboard use. }\end{array}$ & $\begin{array}{l}\text { Access to the } \\
\text { dashboard. } \\
\text { Free-choice to } \\
\text { use the } \\
\text { dashboard. }\end{array}$ & $\begin{array}{l}\text { Access to the } \\
\text { dashboard. } \\
\text { Free-choice to } \\
\text { use the } \\
\text { dashboard. }\end{array}$ & $\begin{array}{l}\text { Access to the } \\
\text { dashboard. } \\
\text { Free-choice to } \\
\text { use the } \\
\text { dashboard. }\end{array}$ & $\begin{array}{l}\text { Access to the } \\
\text { dashboard. } \\
\text { Free-choice to } \\
\text { use the } \\
\text { dashboard. }\end{array}$ \\
\hline
\end{tabular}

We initially explored the community activity during the 6 weeks of the MOOC with four common actions: the designs views, the comments, the profile views and the dashboard views. We counted number of participants who performed those actions throughout the MOOC (see Figure 4).

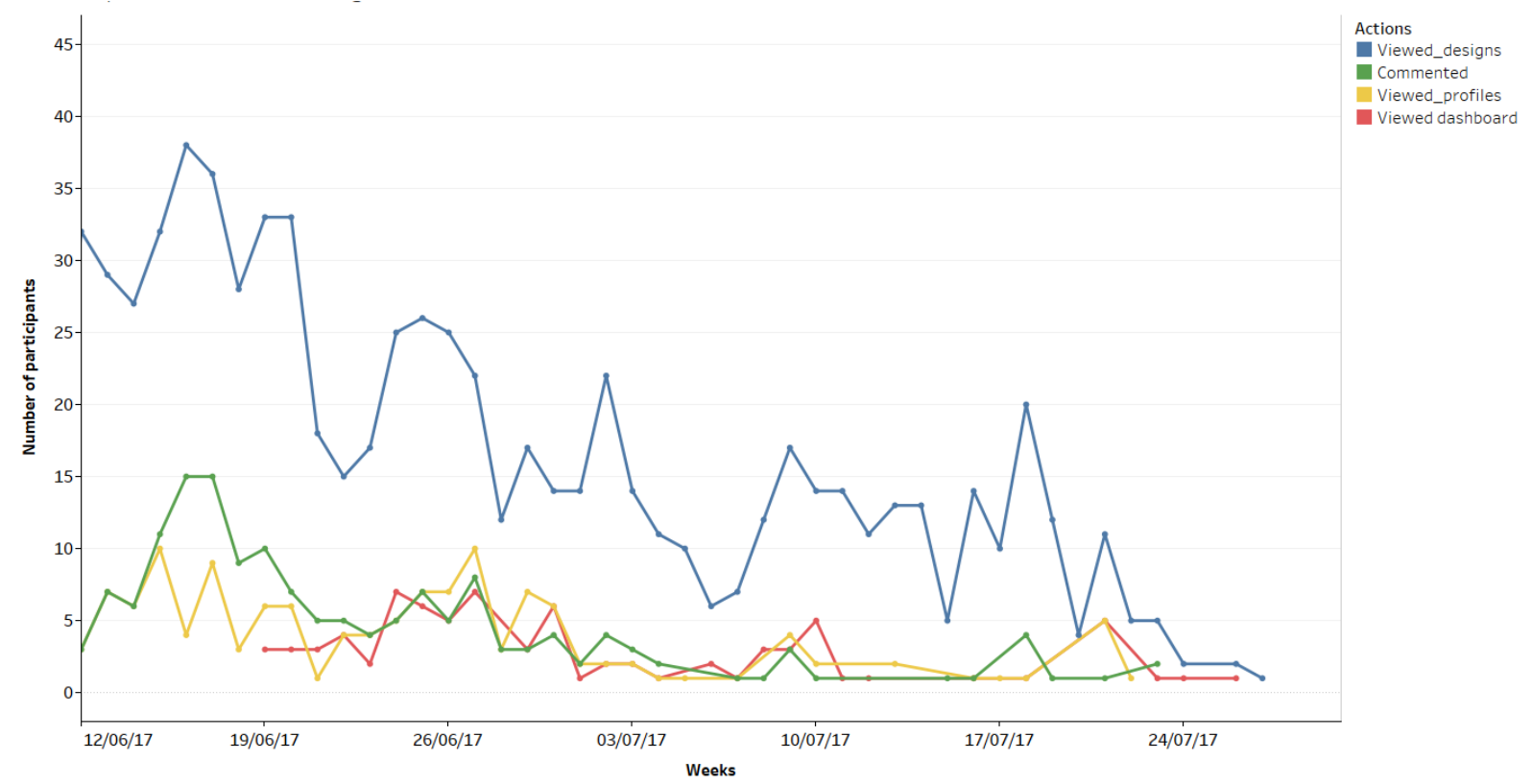

Figure 4. Timeline of participants actions during the MOOC. Viewed_designs: Number of participants viewed a design, Commented: Number of participants commented a design. Viewed_profile: Number of participants viewed a profile. Viewed_ dashboard: Number of participants viewed the dashboard

A decrease of participants with designs views, comments, profiles views and dashboard views was present from Week 1 until Week 6. However, in the last days of Week 2, 3, 4 there was a peak of participants who explored designs and used the community dashboard. The deadlines of the proposed assignments may explain this behavior. 49 out of 100 active participants (created designs $>1$ ) used the community dashboard. To understand the relation between the dashboard views and performed actions 
by participants we conducted a correlation analysis. We included participants who used the community dashboard in the 6 weeks of the course. Spearman's correlation was used because data were not normally distributed (Table 4).

Table 4. Spearman's correlation matrix between dashboard views and participants' performed actions during 6 weeks of the MOOC.

\begin{tabular}{lllllll}
\hline & Mean(SD) & 1. & 2. & 3. & 4. & 5. \\
\hline 1. Dashboard views & $7.90(6.89)$ & & & & & \\
2. Designs views & $146.10(99.99)$ & $.528^{* *}$ & & & & \\
3. Profiles views & $10.24(10.76)$ & $.397^{* *}$ & $.579^{* *}$ & & & \\
4. Comments & $3.51(4.37)$ & $.434^{* *}$ & $.519^{* *}$ & $.394^{* *}$ & & \\
5. Created designs & $8.31(5.63)$ & $.470^{* *}$ & $.758^{* *}$ & $.300^{* *}$ & $.571^{* *}$ & \\
6. Re-used_designs & $7.61(5.52)$ & $.537^{* *}$ & $.783^{* *}$ & $.287^{*}$ & $.544^{* *}$ & $.899^{* *}$ \\
\hline
\end{tabular}

$N=49, * * p<0.01$

There were significant correlations between all the common actions of users (designs views, profiles views, comments, created designs, re-used designs). Regarding the community dashboard the highest moderate positive correlations were between dashboard views and re-use of designs and dashboard views and exploration of designs. This result proposes that the users who explored more the dashboard, re-used more designs and explored more designs or vice versa. We conducted further analysis by each week of the MOOC to better understand the use of the community dashboard. Figure 5 shows higher dashboard use during Weeks 2, 3 while in Weeks 4, 5, 6 there was a significant decrease.

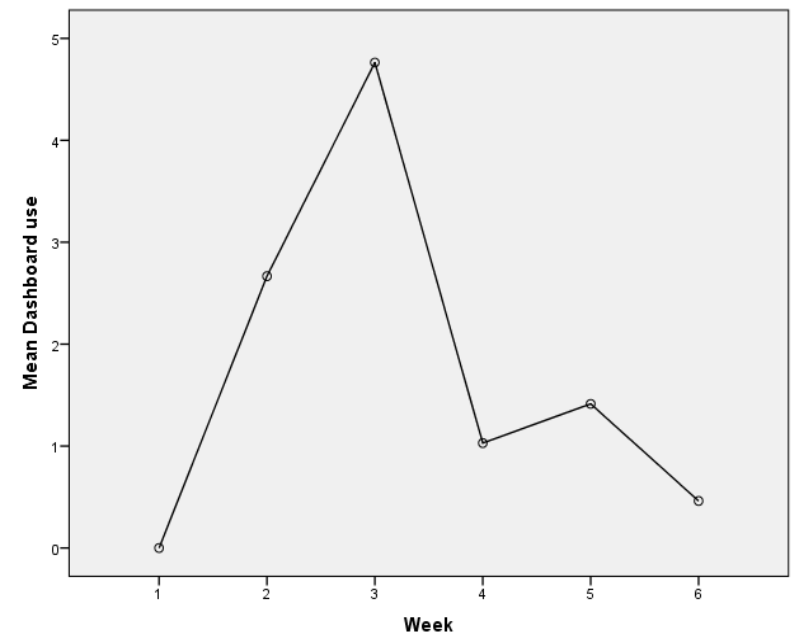

Figure 5 Average dashboard use during the 6 weeks of the MOOC. In Week 1 participants had no access to the community dashboard.

Regarding the influence of the dashboard in the participation behavior of users we performed two types of analysis. First, we compared the actions of the participants during Week 1 (without the dashboard) and Week 2, 3 (with the dashboard). Second, we compared the actions of participants who used more the dashboard compared to participants who used it less.

In the first analysis, Wilcoxon signed rank test (non-parametric repeated measures t-test) was used to compare actions of participants in Week 1 (without dashboard use) and Week 2 and 3 (with dashboard 
use). There were $N=14$ participants who performed actions in Week 1 and used the dashboard in Week 2 , while $N=15$ participants performed actions in Week 1 and used the dashboard in Week 3. Nonparametric t-test was performed for both groups of participants. There was a significant difference $(Z=$ -3.267, $p=.001, r=-0.59)$ with higher profile views between Week 1 and Week 3 but no significant difference $(Z=-2.125, p=.034, r=-0.40)$ between Week 1 and Week 2 . These results propose that dashboard use increased profile views in Week 3.

In the second analysis, we separated the participants who used the dashboard in two equal groups based on the frequency of dashboard views which resulted to $N=24$ participants with low dashboard use and $N=25$ participants with high dashboard use. Our hypothesis was that participants with high dashboard use perform more actions (re-use, creation, comments, edits, exploration of designs) compared to participants with low dashboard use due to awareness support. Shapiro Wilk test showed that data were not normally distributed in both groups except of the variable designs views. Thus, we performed Mann-Whitney $U$ test for independent samples for all the variables and T-test for the variable designs views. Table 5 shows significantly higher profile views and comments for the participants with high dashboard use compared to participants with low dashboard use. However, there were no significant differences in the number of created designs, re-used designs and edits.

Table 5. Results of Mann-Whitney U in high dashboard use vs and low dashboard use groups

\begin{tabular}{llllllll}
\hline Variables & Group & N & Ranks & $\boldsymbol{U}$ & $\boldsymbol{Z}$ & $\boldsymbol{p}$ & $\boldsymbol{r}$ \\
\hline profiles views & High dashboard use & 25 & 31.26 & 138.50 & -3.238 & .001 & -0.46 \\
& Low dashboard use & 24 & 18.27 & & & & \\
comments & High dashboard use & 25 & 30.70 & 157.50 & -2.877 & .004 & -0.41 \\
& Low dashboard use & 24 & 19.06 & & & & \\
created designs & High dashboard use & 25 & 30.12 & 172.00 & -2.570 & .010 & -0.36 \\
& Low dashboard use & 24 & 19.67 & & & & \\
re-used designs & High dashboard use & 25 & 30.08 & 173.00 & -2.547 & .011 & -0.36 \\
& Low dashboard use & 24 & 19.71 & & & & \\
edits & High dashboard use & 25 & 29.60 & 185.00 & -2.335 & .020 & -0.33 \\
& Low dashboard use & 24 & 20.21 & & & & \\
\hline
\end{tabular}

A t-test for independent samples revealed significant difference $t(47)=-3.852, p=.000,95 \%$ CI [46.32, $147.64], d=1.10$ in the group with high dashboard use in designs views $(M=193.60, S D=101.40)$ compared to the group with low dashboard use $(M=96.93, S D=71.63)$. The above results propose that participants who used frequently the dashboard explored more members' profiles and designs in the social platform compared to participants who used the dashboard less. Moreover, participants who used frequently the dashboard wrote more comments.

The participants were asked to perform different epistemic tasks during the MOOC relevant to the design of collaborative learning with ICT. In Week 2 one of the tasks was to comment one case for collaborative learning based on patterns written by another participant and point out the relevance in their own teaching context. Then participants were asked to repeat this task after exploring the visualizations in the community dashboard. To understand differences with/without dashboard use we 
performed content analysis of the messages. The unit of analysis was the sentences in each message. After reading all the messages with/without the dashboard we used an emerging coding scheme about the main topics of the sentences ( $N=69$ coded messages, $N=118$ coded sentences) (See Table 6 ).

Table 6. Coded sentences in the MOOC task with and without the dashboard.

\begin{tabular}{|c|c|c|c|c|}
\hline \multirow[t]{2}{*}{$\begin{array}{l}\text { Code of } \\
\text { sentence }\end{array}$} & \multirow[t]{2}{*}{ Meaning } & \multirow[t]{2}{*}{ Example } & \multicolumn{2}{|c|}{$\begin{array}{l}\text { Frequency of occurrence in the } \\
\text { messages }\end{array}$} \\
\hline & & & $\begin{array}{r}\text { Without the } \\
\text { dashboard }\end{array}$ & $\begin{array}{r}\text { With the } \\
\text { dashboard }\end{array}$ \\
\hline $\mathrm{RC}$ & $\begin{array}{l}\text { Reflecting on the case } \\
\text { in his/her own } \\
\text { context }\end{array}$ & $\begin{array}{l}\text { "I could follow the same in my class where } \\
\text { I teach engineering students to pair them } \\
\text { and give small tasks and then join all the } \\
\text { results to solve the entire problem" }\end{array}$ & 11 & 14 \\
\hline PF & $\begin{array}{l}\text { Positive feedback e.g. } \\
\text { Interesting, very nice }\end{array}$ & $\begin{array}{l}\text { "Very nice practice and very detailed } \\
\text { description." }\end{array}$ & 25 & 25 \\
\hline & $\begin{array}{l}\text { Referring to the } \\
\text { pattern for } \\
\text { collaborative }\end{array}$ & $\begin{array}{l}\text { "We have selected the same pattern to } \\
\text { design the tasks of our collaborative }\end{array}$ & & \\
\hline Pat & learning. & activities." & 13 & 11 \\
\hline Pro & $\begin{array}{l}\text { Making a proposal to } \\
\text { the other participants }\end{array}$ & $\begin{array}{l}\text { "If you really want to do this activity in } \\
\text { your class, the sub-activities should be } \\
\text { explained clearer for the students." }\end{array}$ & 6 & 3 \\
\hline Obs & $\begin{array}{l}\text { Observing other } \\
\text { designs, comments or } \\
\text { titles. }\end{array}$ & $\begin{array}{l}\text { "I chose this case from the } \\
\text { visualizations, because its title deals } \\
\text { with learning and technology, like } \\
\text { mine." }\end{array}$ & 0 & 10 \\
\hline
\end{tabular}

$N=34$ participants completed this task with/without the dashboard. The messages usually included a sentence for positive feedback like "interesting" or "very nice". This occurred equally with/without the dashboard. The main difference with the use of the dashboard was that participants commented more frequently with multiple types of sentences in their comments including positive feedback, reference to the pattern and observations. In particular 10 participants after using the dashboard included in their comments their observations from the visualizations like the different explored designs, the different content in the variations of the same pattern and the titles of the designs ("I chose this case from the visualizations, because its title deals with learning and technology, like mine"). This shows that these participants reflected on others' contributions prior to commenting. Another difference with the use of the dashboard was that participants commented designs that they already included comments because they could see it in the visualization "Top commenters". The depth of the discussion was higher with the dashboard use $(M=2.3, S D=2.01)$ as opposed without the dashboard use $(M=1.32, S D=0.55)$.

During Weeks 3, 4, 5, 6 participants were asked to work on examples of collaborative learning situations based on collaborative patterns (e.g. pyramid, jigsaw). In week 5 participants had to create a learning design project from the conceptualization of a collaborative learning situation to its implementation in a Virtual Learning Environment. Last, in week 6 the main task was to review and evaluate the project of another participant. Regarding the dashboard use for the different tasks, although from Week 3 to Week 6 was periodically decreased, we observed a pattern of highest dashboard use during the first and last day of each week. Participants who used the dashboard explored more frequently the visualization about the members following by visualizations about the designs and then about the tools. 
Regarding subjective usability, out of the 100 active users in ILDE, 40 responded in the final questionnaires (40\%). 29 responders confirmed that they used the dashboard during the MOOC and 11 that they didn't use it. Participants responded that the community dashboard was effective (row Effectiveness) and easy to use (row Overall). However, 12 participants spent too much time to interact with the interface of the dashboard and 4 participants found the experience somewhat frustrating or frustrating (row Satisfaction) (see table 7).

Table 7. Results of the UMUX questionnaire measuring user experience. Likert scale from 1(strongly disagree) to 7 (Strongly agree)

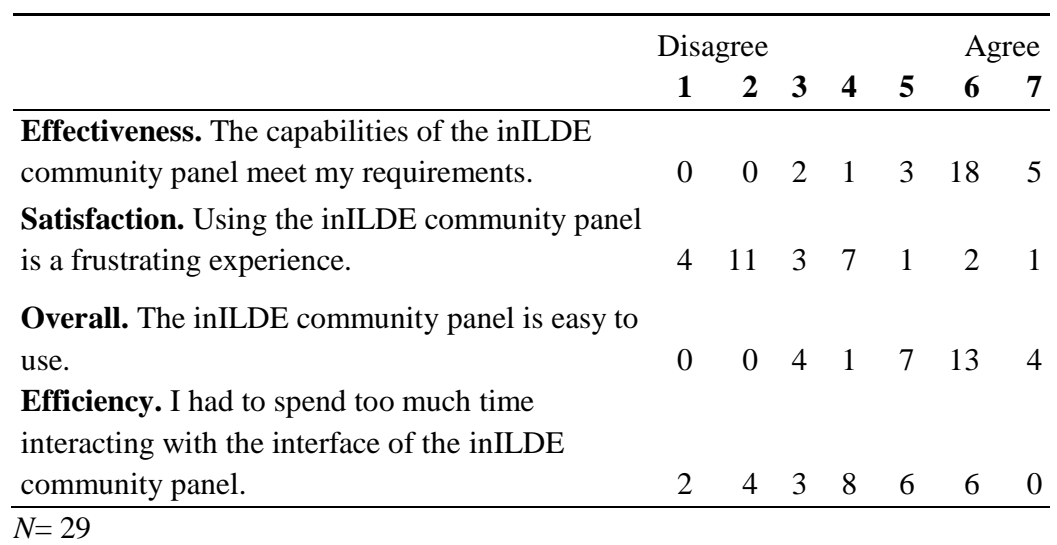

Two additional open-ended questions were used to better understand participants' experiences and how the dashboard facilitated their tasks during the MOOC. The first question was if the community dashboard helped participants to be aware of their community and if and how it facilitated their tasks. Their comments depended on the time they spent using the dashboard. For example, some participants reported limited use but willingness to understand the community through the dashboard. Other participants pointed out that it helped them to search and comment others' designs, re-use designs, get inspiration for ideas and understand the overall activity of the members during the MOOC. Moreover, they mentioned that it helped them to understand which tools were used during the course and their activities in specific time periods of the MOOC. In the second open question participants were asked to write a positive, a negative aspect and a recommendation relevant with the development of the community dashboard. Among the positive aspects were the realization of the sharing possibility in the community, the easy-to-use interface of the dashboard, the opportunity for data-informed search and the variety of the functionalities to continue the learning process in the course. As negative, they mentioned that the dashboard is sometimes difficult to understand so that participants fully benefit from its use. Some recommendations were to group designs according to a topic, the use of badges for the contributors and the use of tools, measurements about the feedback received in learning designs and incorporation of its in more tasks in the training actions.

\section{Discussion}

In this paper, we followed a design based research methodology to develop awareness support in webbased communities for learning design. Our proposal arises from the CHAT framework both for supporting the theoretical understanding of a community of teachers who design innovative learning activities as well as analytical support for community awareness in which units of analysis are defined and displayed as emerging participation metaphors in the community. We worked and investigated our proposal close with school teachers in Secondary and Vocational education, pre-service teachers in a Master course and teachers in a Massive Open Online Course who all used a social platform for learning design named ILDE. Our aim was to build both theoretical understanding on how teachers perceive our 
proposal and second to derive a set of design principles in community awareness support for educational communities. We defined the question on $\mathbf{R Q}$ how community awareness data in such social platforms can help teachers in their learning design process. We first seek to understand $\mathbf{R Q 1}$ which community awareness data and visualizations could be useful in such communities and $\mathbf{R Q 2}$ how community awareness data can be useful in this context. The involvement of different participants in the iterative cycles helped us to compare our results in different educational communities and contexts.

Regarding RQ1 initial analysis of the ILDE (before the development of the awareness dashboard) showed that teachers who used the system during a professional development program reported limited time to explore and share designs both during the workshops and after them. This statement aligns with teachers' time constraints in PLCs (Prenger, Poortman \& Handelzalts, 2017) and informed our development of community visualizations with aggregated data. Teachers showed interest in knowing popular content in their community, how designs are implemented and perceived by students, and willingness to build on others' contributions. This further informs the development of visualizations as a knowledge-creation metaphor and a social process (Paavola, Lipponen \& Hakkarainen, 2004) in such design communities.

The above analysis as well as literature review in communities of learning design led us to develop a community awareness dashboard based on the CHAT framework which displays aggregated and detailed behavioral data regarding the members' actions, the actions performed on the designed artifacts and the actions performed with different tools. In all the cycles participants agreed that the dashboard provides a summary of the community activity and saves their time to identify content which may help reducing time constraints (Jones \& Dexter, 2014). They also agreed that it shows influential members and common interest topics in the community. Specifically, users identified the dashboard as support when they perform joint work with common goals. This reveals that such community dashboard may be used to depict evolving community's interests and members' roles to facilitate knowledge sharing (Chiu, Hsiu, \& Wang, 2006) and community regulation (Klamma, 2013) in specific teachers' projects. They also identified additional use cases of the dashboard as they agreed that facilitates re-use of designs, comments on designs and understanding of the overall use of the tools during different time periods. Their statements helped us to further define the context in which community awareness data can be used for learning design.

As negative aspects, teachers repeatedly stated that the presentation of the dashboard should be linked to the actual artifact or comments. They needed to construct better understanding on what the displayed data mean. For example, they pointed out that in heterogeneous teacher communities with different subject matters, the grouping of designs should be based on topics rather than popular content. Moreover, in teacher communities the display of comparisons related to the contributors was identified as inappropriate. During the MOOC, the visualization for the members' participation was the most used feature, what may show interest of participants to periodically identify most engaged members in their community within a course. In cycle 2 and 3, pre-service teachers in a Master course and the MOOC participants connected the use of the dashboard with the formal tasks proposed by the facilitators. They needed to understand better the displayed data and how this supported their tasks during the course. This shows the relevance of the epistemic tasks and how meditating tools like the community awareness dashboard can lead to meaningful outcomes as defined in the Activity Centred Analysis and Design (ACAD) framework (Goodyear \& Carvalho, 2014).

Regarding RQ2, the pilot study in Cycle 3 showed an influence of dashboard use in exploration of members' profiles in the community, what shows that the dashboard can provide understanding of the social presence in the community (Garrison \& Akyol, 2015). Moreover, high use of the community 
dashboard revealed more exploration of designs, profile views and comments. This shows increased social interactions mediated by the community. Regarding the epistemic tasks during the MOOC, participants that used the dashboard commented designs who received more comments as opposed to those that did not used it and thus were able to reflect more on others' contributions. Dashboard use revealed higher variability in the content of the messages and evidence of participants' reflections about others' designs. User experience was positive with frustrations in the user interface by some of the users. Participants explained that the dashboard helped them to search better the designs and realize the sharing possibility of their community.

\section{Conclusions and future work}

This paper focused on communities of learning design practice supported by a social platform named ILDE. The members of the different communities were teachers in schools, pre-service teachers in a Master course and participants in a Massive Open Online course for learning design. The social platform provides both individual and shared space for teachers to create, share and re-use learning designs. The first stage of the design based research methodology illustrates beliefs of teachers towards sharing the design of learning activities, like willingness to build on other teachers' designs and the need of student feedback. Second, teachers' time constraints hindered the social interactions in the platform like the exploration of material and sharing of resources. Our proposal for community awareness based on the CHAT framework was initially perceived useful as an overall understanding of the community activity and realization of the sharing possibility within the community. The different units of analysis (learning designs, tools, members) were visualized with behavioral data of teachers' interaction with them in the platform. Teachers used the community dashboard during the MOOC with more interest in the visualizations about members' participation behavior in the platform linked with their own artifacts and comments. Blending the community dashboard in MOOC tasks and teachers' face-to-face discussion in workshops showed evidence of community reflection (e.g. review of variations of a design pattern, reading others' comments, understanding of active contributors). Moreover, active users throughout the MOOC who used the community dashboard explored frequently profile of others. In both cases in which the community dashboard was used as support in a formal course, participants needed better understanding on how the community data relate with the proposed task from the facilitators.

The above iterative cycles and observations in the different educational communities helped us to derive in a set of design principles related to awareness support in communities of learning design practice. We classify the principles as follows:

a. Context of the community. Different communities require different types of awareness support according to members' pre-existing relationships, preferences, motivation and curiosity to reveal meaning in the specific educational community. There is no one size fits all solution.

b. Practice-related insights and support. The need to save time, provide subject-related information and align with institutional constraints (e.g. academic program, working life) should be considered. Putting designs in practice and understanding the impression of students needs to be integrated in the community awareness support.

c. Visualizations and representations. Members of the communities need easy-to-understand and explore data visualizations/representations with access to artifacts. The overview of interactions between members, tools and designs can summarize the activity in learning designs communities. Visualizations need to be independent from the platform but relevant with possible performed actions by users.

d. Structured vs. unstructured tasks. Structured learning designs tasks in professional development programs and formal courses which use social platforms require thoughtful 
integration of awareness dashboards to benefit from the community dynamics. Community reflection and discussion tasks can be enhanced with awareness dashboards. When users are engaged in unstructured tasks (e.g. without facilitators' instructions) should consider and benefit from the evolution of participation and members' emerging roles.

e. Interests of community. Community information about methodologies, tools and teacher experiences are the predominant interests. It is important to cultivate community and group work culture within an educational institution. The display of community awareness information between different institutions can create additional interactions.

Our results are strongly related within the context in which were evaluated like school communities and course communities. Thus, it is difficult to generalize to a variety of teaching communities. Moreover, teachers used a specific social platform and thus in other platforms the different interfaces could have different results. However, the development of the community awareness dashboard based on the CHAT framework helps us to align this research with different platforms in which the members, the tools and the designed artifacts can be used as units of analysis for community awareness support. Future work needs to evaluate how the individual interests of users in such social platforms relates with the community provided information. For instance, in our case, the community data can be filtered by specific subject topics to benefit different subject teachers. Another important aspect is how the emerging community information of the dashboard relate with the implementation of the learning designs. For instance, in what extent the most re-used or popular learning designs are perceived as satisfactory by the students. This perspective will need to consider also the students as part of the community or as end users of the created designed products. Future work needs to include metrics about quality and description of designs, feedback given by students and improvements in the interface. We are planning to extend our research in the above educational communities focusing on the interplay between the proposed tasks for learning design and the use of the dashboard to better understand in which specific tasks and how the community dashboard mediates the creation of new learning designs. Last, extension of our work could be performed in other types of authoring communities to better understand how the social space impacts users' interactions and the authoring of new designs in different social platform environments.

\section{References}

Anderson, T., \& Shattuck, J. (2012). Design-based research: A decade of progress in education research?. Educational researcher, 41(1), 16-25.

Asensio-Pérez, J. I., Dimitriadis, Y., Pozzi, F., Hernández-Leo, D., Prieto, L. P., Persico, D., \& Villagrá-Sobrino, S. L. (2017). Towards teaching as design: Exploring the interplay between full-lifecycle learning design tooling and Teacher Professional Development. Computers \& Education, 114, 92-116.

Barab, S., \& Squire, K. (2004). Design-based research: Putting a stake in the ground. The journal of the learning sciences, 13(1), 1-14.

Beetham, H., \& Sharpe, R. (Eds.) (2013). Rethinking pedagogy for a digital age: Designing for 21 st century learning. London: Routledge.

Belkadi, F., Bonjour, E., Camargo, M., Troussier, N., \& Eynard, B. (2013). A situation model to support awareness in collaborative design. International Journal of Human-Computer Studies, 71(1), 110-129.

Bennett, S., Agostinho, S., \& Lockyer, L. (2015). Technology tools to support learning design: Implications derived from an investigation of university teachers' design practices. Computers \& Education, 81, 211-220.

Borges, M., Brézillon, P.A. Pino J.A., Pomerol, J.C. (2005). Groupware System Design and the Context Concept, In Proceedings of the Computer Supported Cooperative Work in Design, 45-54. Heidelberg: Springer Verlag

Brown, R., \& Munger, K. (2010). Learning together in cyberspace: collaborative dialogue in a virtual network of educators. Journal of Technology and Teacher Education, 18(4), 541- 571. 
Shum, S. B., \& Ferguson, R. (2012). Social learning analytics. Journal of educational technology \& society, 15(3), 3.

Carr, S. B., Johnson, N., \& Bush, L. (2017). Distributed Cognition: Teachers' Perceptions and Implications for Learning Outcomes and Instructional Technology. In Educational Leadership and Administration: Concepts, Methodologies, Tools, and Applications (pp. 863-893). IGI Global.

Carroll, J. M., Neale, D. C., Isenhour, P. L., Rosson, M. B., \& McCrickard, D. S. (2003). Notification and awareness: synchronizing task-oriented collaborative activity. International Journal of Human-Computer Studies, 58(5), 605-632.

Catteau, O., Vidal, P., \& Broisin, J. (2008). A Service Providing Awareness of Learning Object Evolutions in a Distributed Environment. In European Conference on Technology Enhanced Learning (pp. 74-85). Springer, Berlin, Heidelberg.

Celik, D., \& Magoulas, G. D. (2016). A review, timeline, and categorization of learning design tools. In International Conference on Web-Based Learning (pp. 3-13). Springer International Publishing.

Chiu, C. M., Hsu, M. H., \& Wang, E. T. (2006). Understanding knowledge sharing in virtual communities: An integration of social capital and social cognitive theories. Decision support systems, 42(3), 1872-1888.

Conole, G. (2008). Capturing practice: The role of mediating artefacts in learning design. In L. Lockyer, S. Bennett, S. Agostinho \& B. Harper (Eds), Handbook of research on learning design and learning objects: Issues, applications and technologies (pp. 187-207). Hersey PA: IGI Global.

Conole, G., \& Culver, J. (2010). The design of Cloudworks: applying social networking practice to foster the exchange of learning and teaching ideas and designs. Computers \& Education, 54(3), 679-692.

Conole, G., McAndrew, P., Dimitriadis, Y. (2010). The role of CSCL pedagogical patterns as mediating artefacts for repurposing Open Educational Resources. F. Pozzi, D. Persico (Eds.), Techniques for fostering collaboration in online learning communities: Theoretical and practical perspectives, (pp. 206-223), IGI Global Publishing

Creswell, J. W., \& Plano Clark, V. L. (2007). Designing and conducting mixed methods research. Thousand Oaks, CA: Sage

Dalziel, J. (2008). Learning design: sharing pedagogical know-how. In: Iiyoshi, T., Kumar, M.S.V. (eds.) Opening Up Education: The Collective Advancement of Education Through Open Technology, Open Content, and Open Knowledge, pp. 375-387. MIT Press, Cambridge

Dalziel, J. (2013). Implementing learning design: A decade of lessons learned. In ASCILITE-Australian Society for Computers in Learning in Tertiary Education Annual Conference (pp. 210-220). Australasian Society for Computers in Learning in Tertiary Education.

Davis, E.A., \& Varma, K. (2008). Supporting teachers in productive adaptation. In Y. Kali, M.C. Linn, \& J.E. Roseman (Eds.), Designing coherent science education: Implications for curriculum, instruction, and policy (pp. 94-122). New York: Teachers College, Columbia University.

Dourish, P., \& Bellotti, V. (1992). Awareness and coordination in shared workspaces. In Proceedings of the 1992 ACM conference on Computer-supported cooperative work (pp. 107-114). ACM.

El-Hani, C. N., \& Greca, I. M. (2013). ComPratica: a virtual community of practice for promoting biology teachers' professional development in Brazil. Research in Science Education, 43(4), 1327-1359.

Engestrom, Y. (2000). Activity theory as a framework for analyzing and redesigning work. Ergonomics, 43(7), 960-974.

Finstad, K. (2010). The usability metric for user experience. Interacting with Computers, 22(5), 323-327.

Fischer, G. (2001). Communities of interest: Learning through the interaction of multiple knowledge systems. In Proceedings of the 24th IRIS Conference (Vol. 1, pp. 1-13). Department of Information Science, Bergen.

Fischer, G., \& Ostwald, J. (2005). Knowledge communication in design communities. In R. Bromme, F. Hesse \& H. Spada (Eds.), Barriers and biases in computer-mediated knowledge communication--and how they may be overcome. Dordrecht, Netherlands: Kluwer Academic Publisher.

Garrison, D. R., \& Akyol, Z. (2015). Toward the development of a metacognition construct for communities of inquiry. The Internet and Higher Education, 24, 66-71.

Gedera, D. S., \& Williams, P. J. (2015). Activity theory in education: Research and practice, Rotterdam: Sense Publishers.

Goodyear, P., \& Carvalho, L. (2014). Framing the analysis of learning network architectures. The architecture of productive learning networks, 48-70. 
Hernández Leo, D., Agostinho, S., Beardsley, M., Bennet, S., \& Lockyer, L. (2017). Helping teachers to think about their design problem: a pilot study to stimulate design thinking. In: Gómez Chova L, López Martínez A, Candel Torres I, (Eds). EDULEARN17 Proceedings 9th International Conference on Education and New Learning Technologies, (pp 5681-5690). Barcelona, Spain

Hernández-Leo, D., Asensio-Pérez, J. I., Derntl, M., Prieto, L. P., \& Chacón, J. (2014). ILDE: community environment for conceptualizing, authoring and deploying learning activities. In European Conference on Technology Enhanced Learning (pp. 490-493). Springer International Publishing

Hernández-Leo, D., Moreno, P., Chacón, J., \& Blat, J. (2014). LdShake support for team-based learning design. Computers in Human Behavior, 37, 402-412.

Janssen, J., \& Bodemer, D. (2013). Coordinated computer-supported collaborative learning: Awareness and awareness tools. Educational Psychologist, 48(1), 40-55.

Jones, W. M., \& Dexter, S. (2014). How teachers learn: the roles of formal, informal, and independent learning. Educational Technology Research and Development, 62(3), 367-384.

Klamma, R. (2013). Community learning analytics-challenges and opportunities. In International Conference on Web-Based Learning (pp. 284-293). Springer, Berlin, Heidelberg

Koch, M. (2005). Supporting community awareness with public shared displays. Proceedings of 18th Bled International Conference on Electronic Commerce, 45. Retrieved January 2018, from https://domino.fov.uni-mb.si/proceedings

Koch, M., Ott, F., \& Richter, A. (2014). Socio-technically Integrated Access to Virtual Communities with Community Mirrors. Virtual Communities, 145-161

Laurillard, D., Charlton, P., Craft, B., Dimakopoulos, D., Ljubojevic, D., Magoulas, G., Whittlestone, K. (2013). A constructionist learning environment for teachers to model learning designs. Journal of Computer Assisted Learning, 29(1), $15-30(2013)$

Lieberman, A., \& Mace, D. P. (2010). Making practice public: teacher learning in the 21st century. Journal of Teacher Education, 61(1-2), 77-88.

Lockyer, L., Bennett, S., Agostinho, S., \& Harper, B. (2009). Handbook of research on learning design and learning objects: issues, applications, and technologies (2 volumes). IGI Global, Hershey, PA.

Ludvigsen, S., Stahl, G., Law, N., \& Cress, U. (2015). From the editors: Collaboration and the formation of new knowledge artifacts. International Journal of Computer-Supported Collaborative Learning, 10(1), 1-6.

Macià, M., \& García, I. (2016). Informal online communities and networks as a source of teacher professional development: A review. Teaching and Teacher Education, 55, 291- 307.

Martinez Maldonado, R., Kay, J., Yacef, K., \& Schwendimann, B. (2012). An interactive teacher's dashboard for monitoring groups in a multi-tabletop learning environment. In Intelligent Tutoring Systems (pp. 482-492). Springer Berlin/Heidelberg.

Martinez-Maldonado, R., Goodyear, P., Carvalho, L., Thompson, K., Hernandez-Leo, D., Dimitriadis, Y., Prieto, L. P., \& Wardak, D. (2017). Supporting collaborative design activity in a multi-user digital design ecology. Computers in Human Behavior, 71, 327-342.

Michos, K., \& Hernández-Leo, D. (2016). Understanding collective behavior of learning design communities. In European Conference on Technology Enhanced Learning, (pp. 614-617). Springer International Publishing.

Mor, Y., Craft, B., \& Hernández-Leo, D. (2013). Editorial: The art and science of learning design. Research in Learning Technology, 21:22513.

Paavola, S., Lipponen, L., \& Hakkarainen, K. (2004). Models of innovative knowledge communities and three metaphors of learning. Review of educational research, 74(4), 557-576.

Papanikolaou, K., Makri, K., \& Roussos, P. (2017). Learning design as a vehicle for developing TPACK in blended teacher training on technology enhanced learning. International Journal of Educational Technology in Higher Education, 14(1), 1-14.

Petrucco, C. (2011). Learning about evaluation and assessment: teacher's use of folksonomies and ontologies in an online narrative environment. Journal of Computer Assisted Learning, 27(5), 399-410.

Prenger, R., Poortman, C. L., \& Handelzalts, A. (2017). Factors influencing teachers' professional development in networked professional learning communities. Teaching and Teacher Education, 68, 77-90. 
Recker, M., Yuan, M., \& Ye, L. (2014). Crowdteaching: Supporting teaching as designing in collective intelligence communities. The International Review of Research in Open and Distributed Learning, 15(4), 138.

Reinhardt, W, Moi, M, Varlemann, T. (2009). Artefact-Actor Networks as tie between social networks and artefact networks. In Proceedings of the 5th International ICST Conference on Collaborative Computing: Networking, Applications and Worksharing (pp 1-10). IEEE: Washington

Ruiz-Calleja, A., Prieto, L. P., Ley, T., Rodríguez-Triana, M. J., \& Dennerlein, S. (2017). Learning Analytics for Professional and Workplace Learning: A Literature Review. In European Conference on Technology Enhanced Learning (pp. 164-178). Springer, Cham.

Saparova, D., Kibaru, F., \& Bašić, J. (2013). Use of widgets as information management tools in online shared spaces. International Journal of Information Management, 33(2), 401-407.

Slotta, J. D., \& Linn, M. C. (2009). WISE Science, Web-Based Inquiry in the Classroom. New York: Teachers College Press.

Schmidt, K. (2002). The Problem with ‘Awareness'. Computer Supported Cooperative Work, 11, 285-298. Kluwer Academic Publisher

Soller, A. (2007). Adaptive support for distributed collaboration. In P. Brusilovsky, A. Kobsa, \& W. Nejdl (Eds.), The adaptive web: Methods and strategies of web personalization (pp. 573-595). Berlin: Springer.

Strauss, A., \& Corbin, J. (1998). Basics of qualitative research techniques. Sage Publications.

Vassileva, J., \& Sun, L. (2007). Using community visualization to stimulate participation in online communities. E-Service Journal, 6(1), 3-39.

Vescio, V., Ross, D., \& Adams, A. (2008). A review of research on the impact of professional learning communities on teaching practice and student learning. Teaching and Teacher Education, 24(1), 80-91.

Voogt, J., Laferrière, T., Breuleux, A., Itow, R. C., Hickey, D. T., \& McKenney, S. (2015). Collaborative design as a form of professional development. Instructional Science, 43(2), 259-282.

Wang, F., \& Hannafin, M. J. (2005). Design-based research and technology-enhanced learning environments. Educational technology research and development, 53(4), 5-23.

Wenger, E. (1998). Communities of practice: Learning, meaning, and identity. Cambridge University Press.

Zhang, J., \& Patel, V. L. (2006). Distributed cognition, representation, and affordance. Pragmatics \& Cognition, 14(2), 333341. 


\section{Appendix}

Table A1. Teachers' responses for awareness support in the ILDE $(N=18)$

\begin{tabular}{|c|c|c|}
\hline \multicolumn{3}{|c|}{ Does ILDE help you be to be aware of the activity done by other members? If yes how? } \\
\hline Coded Category & Example & Frequency \\
\hline Limited time & $\begin{array}{l}\text { "I have not much time to browse other designs. I would like to see what designs } \\
\text { have been implemented and the assessment of other teachers when they put } \\
\text { them into practice." [T10] }\end{array}$ & 5 \\
\hline $\begin{array}{l}\text { Explore, browse, } \\
\text { review }\end{array}$ & $\begin{array}{l}\text { "It helps because it is easy to explore and browse the designs of other } \\
\text { members." [T1] }\end{array}$ & \\
\hline One-word & "No" [T10], “Yes" [T3] & 5 \\
\hline Sharing & $\begin{array}{l}\text { "Yes. You have access to activities shared by other members of the community } \\
\text { that can serve as a starting point for others." [T5] }\end{array}$ & 2 \\
\hline Joint tasks & $\begin{array}{l}\text { "Yes, in the case of common tasks. I suppose if we are involved in joint design } \\
\text { tasks, it is a useful tool." [T6] }\end{array}$ & 1 \\
\hline Comparison & "I compare the work done by other colleagues regarding mine." [T7] & 1 \\
\hline Another subject & $\begin{array}{l}\text { "Yes, it helps to see the activities designed from the perspective of another } \\
\text { subject matter." [T8] }\end{array}$ & 1 \\
\hline
\end{tabular}

Table A2. Teachers' responses about additional community data in ILDE $(N=18)$

Would you like to have additional data regarding the use of ILDE in your community. If yes, which data will be the most interesting for you?

\begin{tabular}{|c|c|c|}
\hline Coded Category & Example & Frequency \\
\hline Most used designs & $\begin{array}{l}\text { "Yes. [I would like to know ...] What are the most used designs, whether it has } \\
\text { worked or not ... to know the contents that worked better." [T18]. }\end{array}$ & 2 \\
\hline Most visited & "Most visited proposals." [T11] & 1 \\
\hline Subject specific & $\begin{array}{l}\text { " [I would like to know ...] areas or topics and within each area by number of } \\
\text { queries, number of times an activity was duplicated, positive comments ..." } \\
\text { [T13] }\end{array}$ & 3 \\
\hline $\begin{array}{l}\text { Impression by } \\
\text { students }\end{array}$ & $\begin{array}{l}\text { "Yes. [I would like to know ...] those that have been most interesting for the } \\
\text { students." [T14] }\end{array}$ & 2 \\
\hline $\begin{array}{l}\text { Activities with } \\
\text { different design tools }\end{array}$ & $\begin{array}{l}\text { "Yes, I would like to see designs related with problem-based learning, webquest, } \\
\text { and other design tools." [T15] }\end{array}$ & 1 \\
\hline Similar resources & $\begin{array}{l}\text { "Yes, [I would like to ...] be informed whether other colleagues use resources } \\
\text { similar to what I use." [T16] }\end{array}$ & 1 \\
\hline Devote more time & $\begin{array}{l}\text { "Yes, I think it would be very interesting, but I would need a constant contact } \\
\text { with the platform and not so sporadic, because then I can understand what } \\
\text { possibilities I had ... etc." [T17] }\end{array}$ & 1 \\
\hline $\begin{array}{l}\text { Interesting without } \\
\text { specifying }\end{array}$ & "It could be interesting." [T21] & 2 \\
\hline No & "No, I do not need." [T22] & 1 \\
\hline Other & "I think the platform should be used more in general." [T24] & 4 \\
\hline
\end{tabular}

$* T 1,2,3 \ldots=$ Teacher response number

Table A3. Teachers'́ responses in School 1 about the usefulness of the community awareness dashboard in Cycle $1(N=13)$.

\begin{tabular}{|l|l|}
\hline Visualizations about designs & Visualizations about community members \\
\hline "Everything seems good to me." [T30] & "Everything seems right to me.."[T44] \\
"It already seems good to me." [T31] & "I find it ok. “[T45] \\
" The information to find the most used or duplicated designs & "Tool not so much intuitive." [T46]
\end{tabular}


is interesting, maybe it could directly appear the works or designs properly linking with them." [T32]

"The positive aspect is that from this platform I can see the summary of my community in a dynamic and fast way, but as a negative point is that if my community is very

heterogeneous in terms of the subjects which we represent,

some tools are not useful for me." [T34]

"It's good to get an idea of what is most used and therefore it can be more useful for not "losing" so much time searching. It is a more immediate search." [T35]

“... It can be useful in the case of greater use and a larger community of users (for example, from various schools and institutes), then this tab could be an improvement in the tool ."[T36]

"Positive: It is possible to know the "best" designs.

Negative: It is not evident." [T37]

"Positive: it allows to visualize the role and participation of the different members.

Negative: It introduces an aspect of comparison that cannot always be good among teachers." [T38]

"Positive aspect: it gives a very graphical comparison." [T39]

"Positive aspect: overview of all the information." [T40]

"It helps us to identify those most popular, most used designs ... Only a certain number of people appear in the ranking, not everyone / all designs appear. ” [T41]

"I'm sorry but I would need more time to point out negative aspects. " [T42]

"I think that, while being quite useful, the interface is not intuitive and not too attractive." [T43]

$* T 1,2,3 \ldots=$ Teacher response number
"It is useful to recognize the most active users in the community but I do not see the utility for using the different tools, since regardless of the top users it may be very different from my profile and his contributions do not interest me." [T48]

"It's good to be able to put in common with these people who use these tools more and to be able to share." [T49]

"They are very visual and stand out the most active members and the ones who make the most out of it. It may be useful to identify users who do not benefit from the tool and check for possible improvements." [T50]

"It could be an aspect to improve if the comments are useful or significant." [T51]

"Positive: it allows to see the own level of participation and the others Negative: I do not understand how the top commenters contribute." [T52]

"Positive: the global vision. To be improved: to appear who are the members." [T53]

"Positive aspect: overview of all the information." [T54]

"Positive: it helps us see the degree of participation of the members of the community. Negative: From here we cannot (directly) access their contributions." [T55]

"It is mostly quantitative." [T56]

"I think it's not clear how to sort the columns." [T57]

Table A4. Quote of discussion between facilitator and teachers during a workshop for learning design in Cycle 2.

Teacher \#1: “Actually, if we had a similar tool to track our students, to see what our students are doing that would be great!”. Then many teachers started to laugh.

Teacher \#2: "But this is only between us? So the presented data is about our interaction with the platform."

Facilitator of the workshop: “...Yes, they are about the use of ILDE by your group of teachers.”

T2: "For me it looks very interesting to be able to evaluate during the term, what really happens during a whole course. a) Which are the teachers who are working and design together, and which are $b$ ) the main themes and most interesting tools used. I think for this purpose it is useful. This is something that we miss. However, I cannot think of how to use it, because for example here we have never done it in the educational center to supervise the our work or to know what kind of person works with whom. For example, we do not have a summary or history of projects in which we worked together."

Faciliator of the workshop: "The dashboard is showing awareness data to see the evolution of the community and not as an evaluation tool between teachers."

Teacher \#3: "Yes I understand what do you say. What I want to say is that I find it interesting because we do not have this community culture. We used to work on our subjects but we do not have the culture of community to share the experiences of our work. I think it's a matter of work method: I have realized that 
sometimes we are using methodologies that are the same, doing the same, and we have not realized until we have shared the subject. And maybe we do not know how to take advantage of that. "

Table A5. Responses in School 2 and Master course about the usefulness of the community awareness dashboard during Cycle $2(N=36)$.

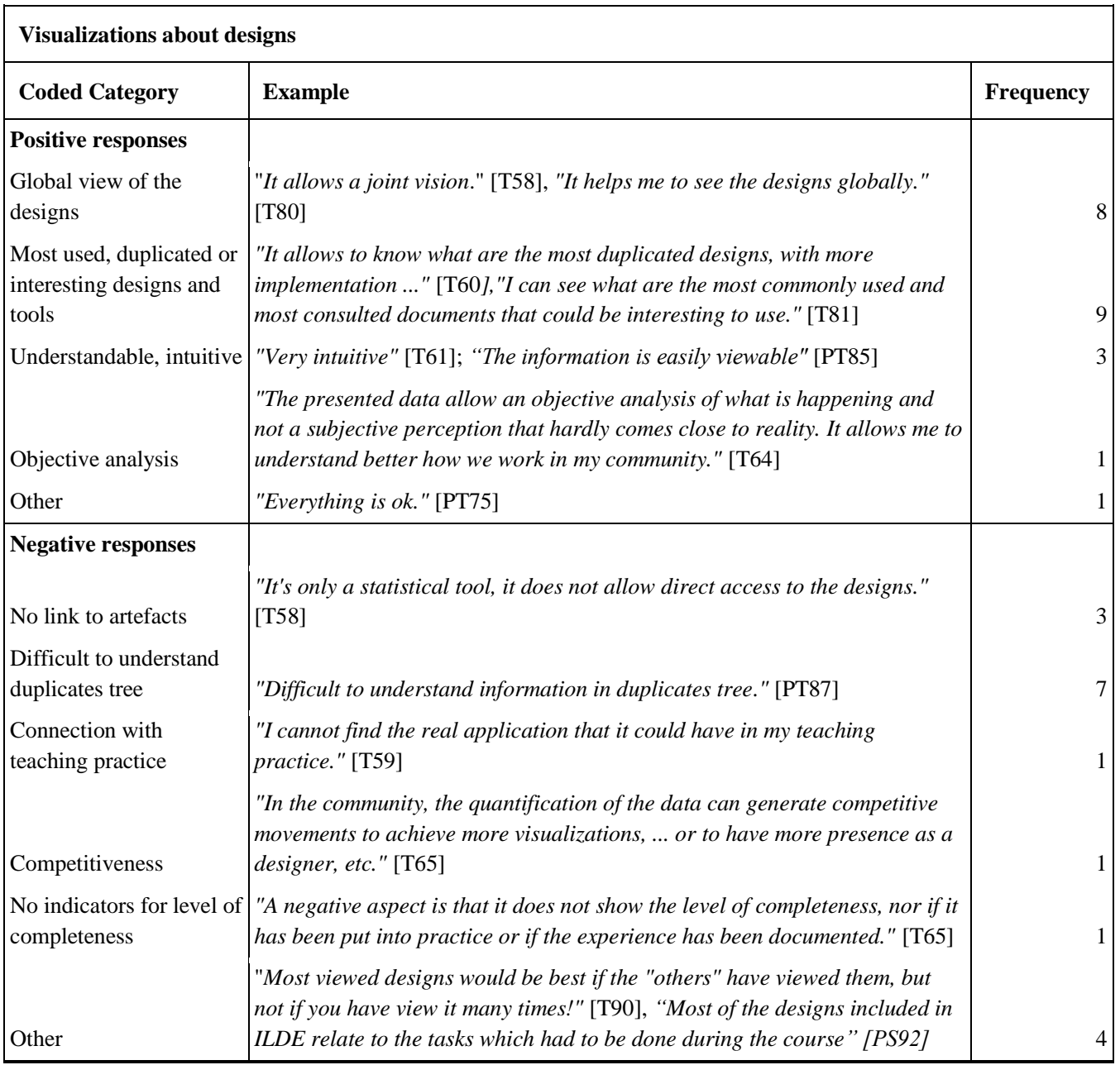

$* T 1,2,3 \ldots=$ Teacher response number, $P T 1,2,3 \ldots=$ Pre-service teacher response number

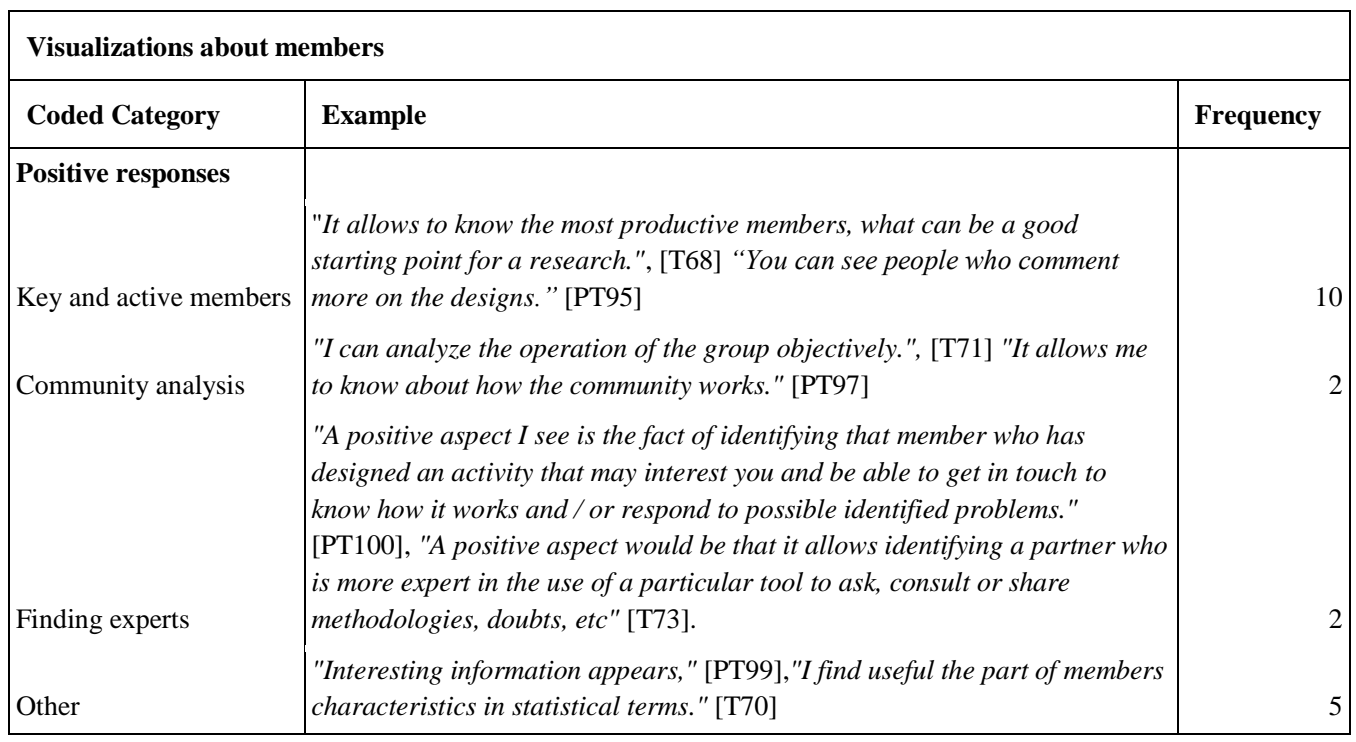




\begin{tabular}{|l|l|l|}
\hline Negative responses & $\begin{array}{l}\text { "The number of contributions can sometimes lead to deception. It is } \\
\text { quantitative value, but not qualitative. In certain circumstances, an excess of } \\
\text { participation can be interpreted negatively ("I no longer do it because they } \\
\text { always speak of everything and do not always add added value")." [T69] }\end{array}$ \\
$\begin{array}{l}\text { Quantities vs. qualities } \\
\text { Applicability of } \\
\text { information }\end{array}$ & $\begin{array}{l}\text { "In some cases, it might not interest someone and that a person makes less } \\
\text { comments." [PT100] } \\
\text { "It does not describe well the tasks each one has done. I appear there and I } \\
\text { think I have not contributed so much as to appear." [PT101] } \\
\text { "We worked in pairs and one did the actual comment." [PT101] }\end{array}$ & 5 \\
Work in pairs & 1 \\
\hline
\end{tabular}

$* T 1,2,3 \ldots=$ Teacher response number, $P T 1,2,3 \ldots=$ Pre-service teacher response number

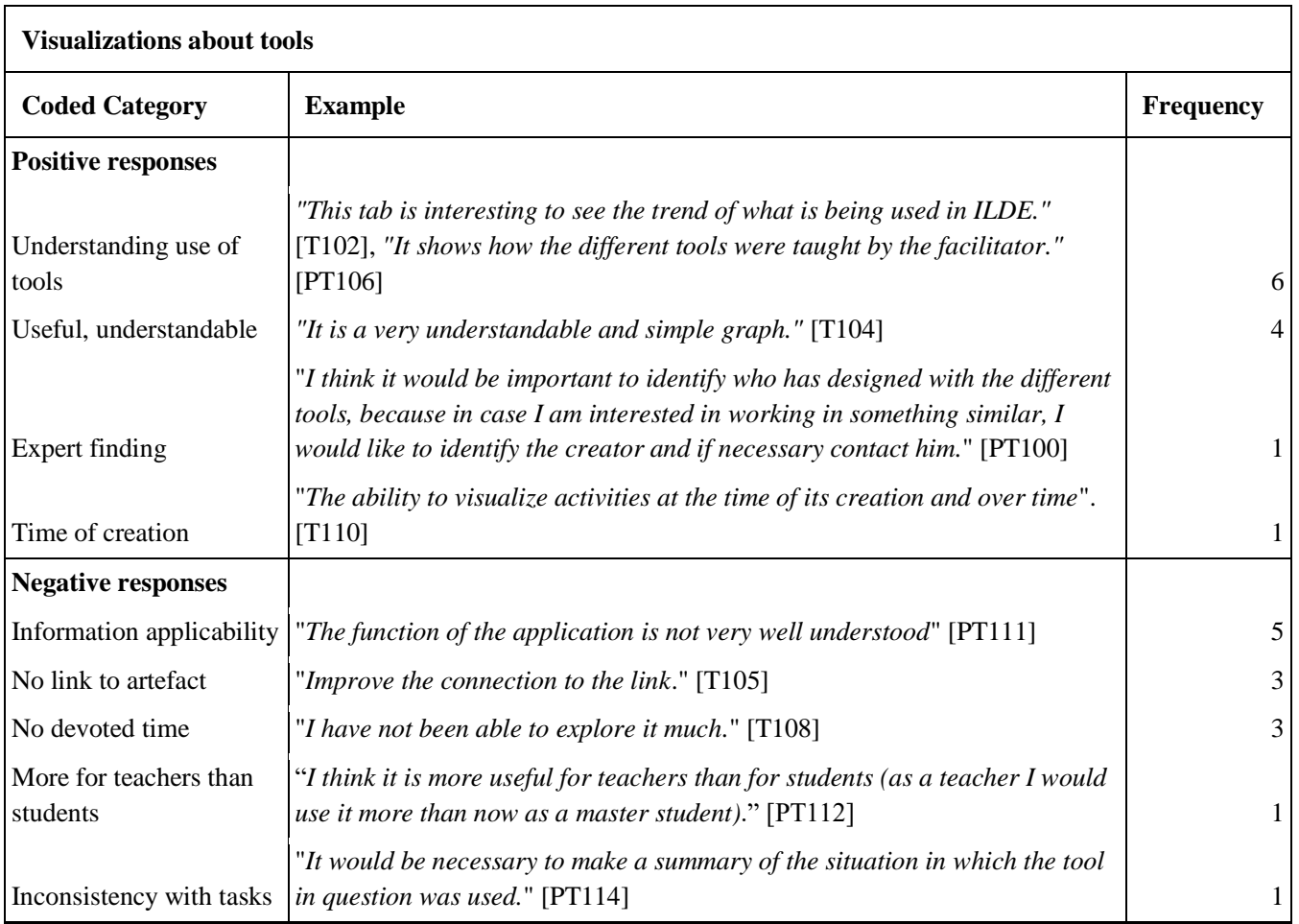

$* T 1,2,3 \ldots=$ Teacher response number, PT1,2,3 $\ldots=$ Pre-service teacher response number 